\title{
How to Perform a Reliable Full Spine X-ray Examination in Juvenile and Adolescent Scoliosis.Experience outcome
}

Sergio Palandri ( $\nabla$ danaskully@bl1036.org )

AO Ordine Mauriziano di Torino https://orcid.org/0000-0001-9776-3618

\section{Technical advance}

Keywords: scoliosis, X-ray, spine, technique

Posted Date: December 2nd, 2020

DOI: https://doi.org/10.21203/rs.3.rs-28300/v2

License: (c) (i) This work is licensed under a Creative Commons Attribution 4.0 International License.

Read Full License 


\section{Abstract}

\section{Background:}

lonizing radiations, even at low doses, present side effects that are known as well as girls and toung women constitute the most sensible individuals from a radioprotectional point of view.

On the other side full spine x-ray radiography is the gold standard in diagnose and follow-up of AIS, where individuals involved are typicaly girls and young women.

For these reasons, a partuicular care permorming radiographics esamination in this scope, in mandatory.

The aim of this work is to provide a simple and detailed protocol to perform full-spine X-ray examination in diagnosis and follow-up of AIS

This paper is the result of our experience along 7y of work in application and study of the scoliosis in the first two decades of life, combining the orthopaedist's requirements, the surgical requirements along with the care for the particularly significant relational feature, due to the specific category of most individuals undergoing this radiological examination.

\section{Methods:}

For the maximum usability and Clarity, we considered three main topics: a) single examination b) examination during orthotic treatment and c) pre-op control. For each one we explained number and type of X-ray view used and how we performed them with the assistance of detalide figures.

\section{Results:}

By comparing X-ray images before and after the application of our protocol, we saw a significant increase in the quality of the produced images as well as a positive feedback from patients and parents acceptance.

\section{Conclusions:}

An extended collaboration between the Orthopaedic Surgeons and the Radiographer, has led to a clear improvement in technical execution and in an exposure dose reduction. Furthermore a particular attention to the patient's comfort, along with some technical stratagems, led to an improving effectiveness of the services supplied.

\section{Introduction}

The side effects of the ionizing radiations are well known and the individuals most exposed to such radiations belong to female gender, particularly if in young age, above all when undergoing repeated X-ray check-ups for scoliosis [1-2]. 
Scoliosis is a genetically-based, polygenic and multi-factorial pathology which implies a structured deviation of the spine in the coronal plane, along with an axial rotation of the vertebral bodies, either in the thorax or lumbar section, or in both ones.

Its onset mainly occurs at pre-puberty / puberty and in case of evolution girls are more affected than boys, with a ratio of 10:1, as reported by Horne, Flannery and Usman [3] in an article published in 2014. In the same article the authors state that the diagnosis is clinic (physical examination), but the measurement of the curvature angle (Cobb angle) is only possible through a radiographic examination, known as spine teleradiography or standing full-spine $X$-ray.

Determining the value of the curvature angle is significant for the treatment: during puberty curves up to $20-25^{\circ}$ will be assessed, for greater values (up to $40-45^{\circ}$, values greater than these require surgery) a brace treatment will be planned with periodic both clinic and $\mathrm{x}$-ray assessments. Therefore, the use of ionizing radiations is necessary both from a diagnostic and a follow-up point of view, as able to prove and quantify the state of the pathology and the effectiveness of the treatment.

Even if these investigations imply an exposition to low doses of ionizing radiations, these cannot be undervalued. Indeed, studies published already in 2013, but lately in 2018 and 2016 [4-5], reported how, even though there aren't any definite data yet, low doses are likely to be involved in an increasing risk of cancer or other kinds of pathologies (e.g. cardiovascular problems and malformations). Therefore, the authors, Knüsli and Walter [6], Arthurs and Bjørkum [7] recommend to avoid, when possible, the exposition to ionizing radiations in individuals in prepuberal an puberal age. Furthermore recently Meulepas et al. and Baaken et al. in their article publlished in 2019 restated the health risk using diagnostic X-ray exposure in childhood [8-9].

A reduction in the dose for the patient goes through the right technology and of course through the experience and knowledge of the problems concerning the x-ray examination itself and its appropriate use. This necessarily implies an effective synergy between Orthopedics Specialist, Radiologist and Radiographer. Especially about Radiographer task, the relational approach is extremely important too, because most of them are girls o young women in a phase of critical psychophysical development.

This work arises from the idea of combining in a single paper the long experience of application and study of the scoliosis in the first two decades of life, from an X-ray point of view.

The orthopaedist's requirements, the surgical requirements along with the care for the particularly significant relational feature, as already said, due to the specific category of most individuals undergoing this radiological examination, have increased the knowledge which is basically common to every Radiographer but has many disregarded and unknown aspects.

\section{Methods}


To organize the current work in the simplest way, we identified the main reasons or conditions which lead to the prescription of a standing full-spine X-ray. Specific view and conditions to perform them according to the situation are also examined.

\section{A) Single check-up}

\section{a. 1 indications}

It represents the first radiographic evaluation, following a prescription by the Specialist who observed the presence of a hump during the physical examination.

\section{a.2 setting of the patient}

During the examination the patient only wears her/his underwear (not the vest). Girls and young women should wear a sports bra, without any metal parts, otherwise the Radiographer will give them something to cover their breast.

As for any X-ray examination, the patient will need to remove any metal objects from around the area to be examined (neck, thorax and abdomen), e.g. necklaces, earrings, piercings.

\section{a.3 preliminary assessment}

The main aim of every X-ray is to give diagnostic images.

For this reason and for an adequate positioning of the lead shield, especially for breasts, it is appropriate to perform an accurate assessment of the patient.

Such assessment does not have and cannot have a diagnostic purpose, but it is carried out to understand the patient's habitus for a better X-ray.

It consists in observing the patient in the coronal plane both in antero-posterior and postero-anterior view, highlighting shoulder and iliac crest asymmetries, as described in Fig. 1, and in anterior bending of the trunk (Adam's forward bend test), to notice any humps, as shown in Fig. 2, for an adequate positioning of the lead shields. For this reason, the Radiographer, looking at her antero-posteriorly, should trace an imaginary line connecting the spinous processes of the patient in standing position (marked by his thumb) with the ipsilateral breast (marked by his index finger) to clear potential overlapping, as shown in Fig. 3.

\section{a.4 Antero-Posterior (AP) view}

Positioning the shields in male patients is easier: the lead shield will be positioned on the genitalia and, if conceived without specific strings, it will be kept in position with fabric plaster.

In girls and young women, the positioning is more complex. At the genitalia level the lead shield, positioned with the superior edge on the line joining the Antero Superior lliac Spine (ASIS) (see Fig. 4), 
covers the inferior $2 / 3$ of the distance between the iliac crest and the greater trochanter.

Both in female and male gender, Risser's sign is fundamental to correctly evaluate the X-ray image result, so is mandatory to avoid use of aperture.

To protect the breasts shaped models of the appropriate size can be used; the lead shield must not overlaps the potential scoliotic deviation. Depending on the model of the shields available, the two parts (right and left) can be tied together with a string behind the neck (see Fig. 5) or with a fabric plaster. Once checked the correct positioning, it is advisable to fix them with a strip of fabric plaster so that they can't move in the coronal plane.

When standard devices cannot be used, most of the breasts on the side of the scoliotic deviation can be covered with other differently-sized lead shields. When neither this is possible, the breast on the side of the curve will not be covered, while the contralateral side will be covered as usual, as shown in Fig. 6 . The positioning of the patient in relation to the X-ray film is very important too, as the correct measurement of the Cobb angle depends on this.

The patient stands perfectly parallel to the X-ray film and leaning against it. The potential presence of humps will limit the contact only on the side where the hump is present.

To verify that no rotation is present in the axial plane of the shoulder girdle, place your thumbs on the humeral lesser tuberosities and wrap the shoulders with your fingers, you will check if the virtual line joining the humeral lesser tuberosities is parallel to the $\mathrm{X}$-ray film.

Likewise, you must verify that no rotation of the pelvic girdle is present, measuring by touch the distance of the ASIS from the X-ray film, placing your hands by the patient's hips: with the tip of the middle finger touching the X-ray film and your thumbs on the ASIS, the patient will be perfectly parallel to the X-ray film if your hands are equally stretched and the patient does not have one or both knees bent (Fig. 7). If the patient's habitus could not allow the simultaneously positioning of the thumbs on the ASIS and of the tip of the middle fingers on the X-ray film, the perceptive sensation of the Radiographer will ensure the best possible positioning.

The head must be in a neutral position, with no hyper-extension or hyper-flexion, looking at the horizon, without clamping your teeth or having them resting together (stomatognathic apparatus in neutral position).

The upper limbs must rest along the body, slightly abducted in the coronal plane to exclude them from the Field of View (FOV) of the X-ray. Feet are parallel and close, but not with any contact points included medial malleolus. Take care to exclude crystalline lens from FOV by using appropriate aperture. The correct positioning is shown in Fig. 8.

The right positioning before and during the $\mathrm{x}$-ray examination also goes through an efficient relationship with the patient, who has to be involved as an active part during the examination, adequately informed, 
and has to feel comfortable. The time spent talking with patient and her/his parents about the examination and answering their questions, is not wasted but it is fundamental to have a good final Xray.

\section{a.5 Side view}

What already said in a.4 also is valid for this view, with some specifications.

First, the lead shields will be replaced to better protect the genitalia and, in girls and young women, the breast on the side contralateral to the one chosen for the view. Shields must not be placed posteriorly beyond the vertical line passing through the acoustic meatus, acromion, greater trochanter and the lateral malleolus, in order not to cover, at lumbar level, the anterior wall of L5.

The choice of the side follows the classic rules of radiology: a right convex curve requires a right view, and a left convex curve requires a left one. The reference must be the main curve in presence of a compensating curve and, in case of a double or triple curve, the clinically most evident. In the lateral view, the upper limbs will be bent, the tip of the fingers resting over the ipsilateral clavicle, slightly moving the elbows onwards in order not to mask the lumbosacral joint. In this way, the dorsal kyphosis will not be misrepresented. The correct positioning is shown in Fig. 9

\section{B) examination during orthotic treatment}

\section{b.1 indications}

When patients undergo orthotic treatment, a comparison with the previous clinic examination is necesssary to show a worsening of the curve.

\section{b.2 preparation of the patient}

See point a.2

\section{b.3 preliminary assessment}

See point a.3

\section{b.4 AP view}

Since previous examinations have already shown the patient's clinic condition, except for particular clinic needs underlined by the Orthopaedist, we can perform the examination only in this view due to radioprotection reasons, even if literature is not unanimous. Furthermore, as the interpretation in literature is ambiguous, the patient should not have worn the corset or the orthotic device for at least 12 hours before the X-ray examination, to avoid mistakes deriving from the persistence of the corrective effect of the orthosis itself.

For any other aspects, what described in a.4 also applies here. 


\section{C) Pre-operating control}

\section{c. 1 indications}

Literature suggests surgery for curves with Cobb angle greater than $40-45^{\circ}$. If surgery is the decision, a targeted radiology examination must be part of the pre-op practice, which, as to the Conventional Radiology, consists of the X-rays which will be hereafter specified.

\section{c.2 preparation of the patient}

See point a.2.

\section{c.3 preliminary assessment}

See point a.3.

\section{c.4 AP view}

See point a.4.

\section{c.5 Side view}

See point a.5.

\section{c.6 Corrective bending of the lumbar curve}

This is a normal AP view with patient lateral bent towards the convexity side of the lumbar curve: for instance, in a left lumbar curve, improvement (that is the decrease in the bending angle) will be achieved with a left lateral flexion and vice versa in case of a right-convex curve.

As to the performing techniques, what described in c.4 for AP view also applies here with some specifications explained below.

The patient must not lose the parallelism with the X-ray film during lateral flexion.

Depending on the patient's habitus, it may not be possible to include both the greater trochanter and the iliac crest opposite to the bending within the dimensions of the FOV connected to the film, but this isn't a high-priority task. Obviously, the lumbar spine must be completely represented.

In this view, attention must be paid to the positioning of the breast lead shields: if they are not well fixed, they can move, compromising the quality of the images, as shown in Fig. 10.

\section{c.7 prone position (or prone view)}

To facilitate the Orthopaedist in the operating planning, an X-ray view adhering as much as possible to the patient's position on the operating table has been thought. 
For this view, the Multi-Potter used in orthostatic position, must lay on horizontal X-ray table (radiographers using a Direct Radiology (DR) system with specific programs must check if they can modify in order to be used in clinostatic position). Adequate pre-shaped supports will be placed on it to allow the thorax, pelvis and lower limbs to lean over them (Fig. 11).

If pre-shaped supports are not available, you can have a similar effect rolling up sheets with an adequate size and putting them at clavicular, sub-mammary and ASIS level. With other available support, you will provide a support elevating lower limbs.

In this way you must ensure a correct expansion of the thorax during the breathing phases and the completely lack of compression of aorta at abdominal level.

The lower limbs sticking out of the Multi-Potter must be supported with polystyrene-like wedges to elevate the forearms.

The forehead will rest on a pillow so that the whole spine can be aligned without any axial rotations (avoiding patient lying on his cheek).

Arms will be bent at $90^{\circ}$ angle with hands at head level in the horizontal plane, as shown in Fig. 12, Fig. 13, Fig. 14 and Fig. 15.

In female gender patients, lead shields will be placed on the back in front of the segments to be protect. Here their positioning will be much easier than in the orthostasis (Fig. 16, Fig. 17, Fig. 18 and Fig. 19).

The FOV will be considerably reduced due to the structure of the system planned; however it will be wide enough to contain the scoliotic curve.

During the post-processing phase, it is highly advisable to highlight the right and left side with letters and to stick a label suggesting that the patient is in prone position.

\section{Results}

when applied as we have presented above, our protocol demostrated its efficacy in obtaining better images both under a clinical pont of view and a technical one.

This is easly observable comparing the radiographical results shown in Fig. 20, where tipycaly positioning and technical mistakes are present, and the one shown in Fig. 21, where those mistake are not present.

Note that the better results depend on an enhancement in technical management of the exam (positioning, vertical aperture) and at the same time an enhancemnt in building a relationship with Patient and her/his parent. 


\section{Discussion}

Articles providing operating procedure to perform a high quality full-spine x-ray examination both under clinical, technical and relational point of view, are so rare in letterature. This paper is built on our daily work experience over seven years and we have found a significantive improvement in performing this type of examination by using the criteria we explained above.

On the other side we are aware that only a sistematic upgrade in practice, skills, knowledge and collaboration among all professional figures involved, Orthopedist, Radiologist and Radiographer, can lead to a really high level of quality in the service provided.

\section{Conclusions}

A continuous collaboration and integration among the different professionals involved in the care pathway of the scoliotic patients has led to a clear improvement both in technical execution and in dosimetric accuracy. Attention to the patient's comfort, along with some technical stratagems, here explained, led to an improving effectiveness of the services supplied.

\section{Abbreviations}

\begin{tabular}{|ll|}
\hline ABBREVIATION & MEANING \\
\hline AP & Antero-Posterior \\
\hline ASIS & Antero Superior lliac Spine \\
\hline FOV & Field of View \\
\hline DR & Direct Radiology \\
\hline
\end{tabular}

\section{Declarations}

\section{Ethics approval and consent to participate}

Not applicable

\section{Consent for publication}

the young woman in figures is no a Patients, but a model who kindly voluntered to let us support our article. She verbally agrees to publish these figures concealing her face as we done

\section{Availability of data and material}




\section{Competing interts}

The authors declare that they have no competing interests

\section{Funding}

There are no sources of funding for this work

\section{Authors' contributions}

PS and TF equally contrubute to design, built and realise this work, especially bringing about their specific professional skills and experience.

All authors have read and approved the manuscript

\section{Acknowledgements}

I feel to thanks never enough Fabrizio Trucchi MD for his great contribution in built this article as well as his friendship.

\section{References}

1. Michele Morin Doody, MS, John E. Lonstein MD, Marilyn Stovall, PhD, David G. Hacker, BS, Nickolas Luckyanov, PhD, Charles E. Land, PhD, Breast Cancer Mortality After Diagnostic Radiography.

Findings From the U.S. Scoliosis Cohort Study.. SPINE 2000 Volume 25, Number 16, pp 2052-2063

2. Cécile M. Ronckers, Michele M. Doody, John E. Lonstein, et al., Multiple Diagnostic X-rays for Spine Deformities and Risk of Breast Cancer.. Cancer Epidemiol Biomarkers Prev 2008;17:605-613.

3. Horne JP, Flannery R, Usman S. Adolescent idiopathic scoliosis: diagnosis and management. Am Fam Physician. 2014 Feb 1;89(3):193-8. PubMed PMID: 24506121.

4. Tang FR, Loganovsky K. Low dose or low dose rate ionizing radiation-induced health effect in the human. J Environ Radioact. 2018 Dec;192:32-47. doi:10.1016/j.jenvrad.2018.05.018. Epub 2018 Jun 5. Review. PubMed PMID: 29883875.

5. Baselet B, Rombouts C, Benotmane AM, Baatout S, Aerts A. Cardiovascular diseases related to ionizing radiation: The risk of low-dose exposure (Review). Int J Mol Med. 2016 Dec;38(6):16231641. doi: 10.3892/ijmm.2016.2777. Epub 2016 Oct 17. Review. PubMed PMID: 27748824; PubMed Central PMCID: PMC5117755. 
6. Knüsli C, Walter M. [Update - health risks induced by ionizing radiation from diagnostic imaging]. Ther Umsch. 2013 Dec;70(12):746-51. Doi: 10.1024/0040-5930/a000474. Review. German. PubMed PMID: 24297861.

7. Arthurs OJ, Bjørkum AA. Safety in pediatric imaging: an update. Acta Radiol. 2013 Nov;54(9):983-90. doi: 10.1177/0284185113477399. Epub 2013 Apr 30. Review, PubMed PMID: 23550188.

8. Meulepas JM, Ronckers CM, Smets AMJB, Nievelstein RAJ, Gradowska P, Lee C, Jahnen A, van Straten M, de Wit MY, Zonnenberg B, Klein WM, Merks JH, Visser O, van Leeuwen FE, Hauptmann M. Radiation Exposure From Pediatric CT Scans and Subsequent Cancer Risk in the Netherlands. J Natl Cancer Inst. 2019 Mar 1;111(3):256-263. doi: 10.1093/jnci/djy104. Erratum in: J Natl Cancer Inst. 2018 Oct 1;110(10):1154. PubMed PMID: 30020493; PubMed Central PMCID: PMC6657440.

9. Baaken D, Hammer GP, Seidenbusch MC, Schneider K, Spix C, Blettner M, Pokora R, Lorenz E. Second follow-up of a German cohort on childhood cancer incidence after exposure to postnatal diagnostic x-ray. J Radiol Prot. 2019 Jul 25;39(4):1074-1091. doi: 10.1088/1361-6498/ab3506. [Epub ahead of print]. PMID:31342929.

\section{Figures}




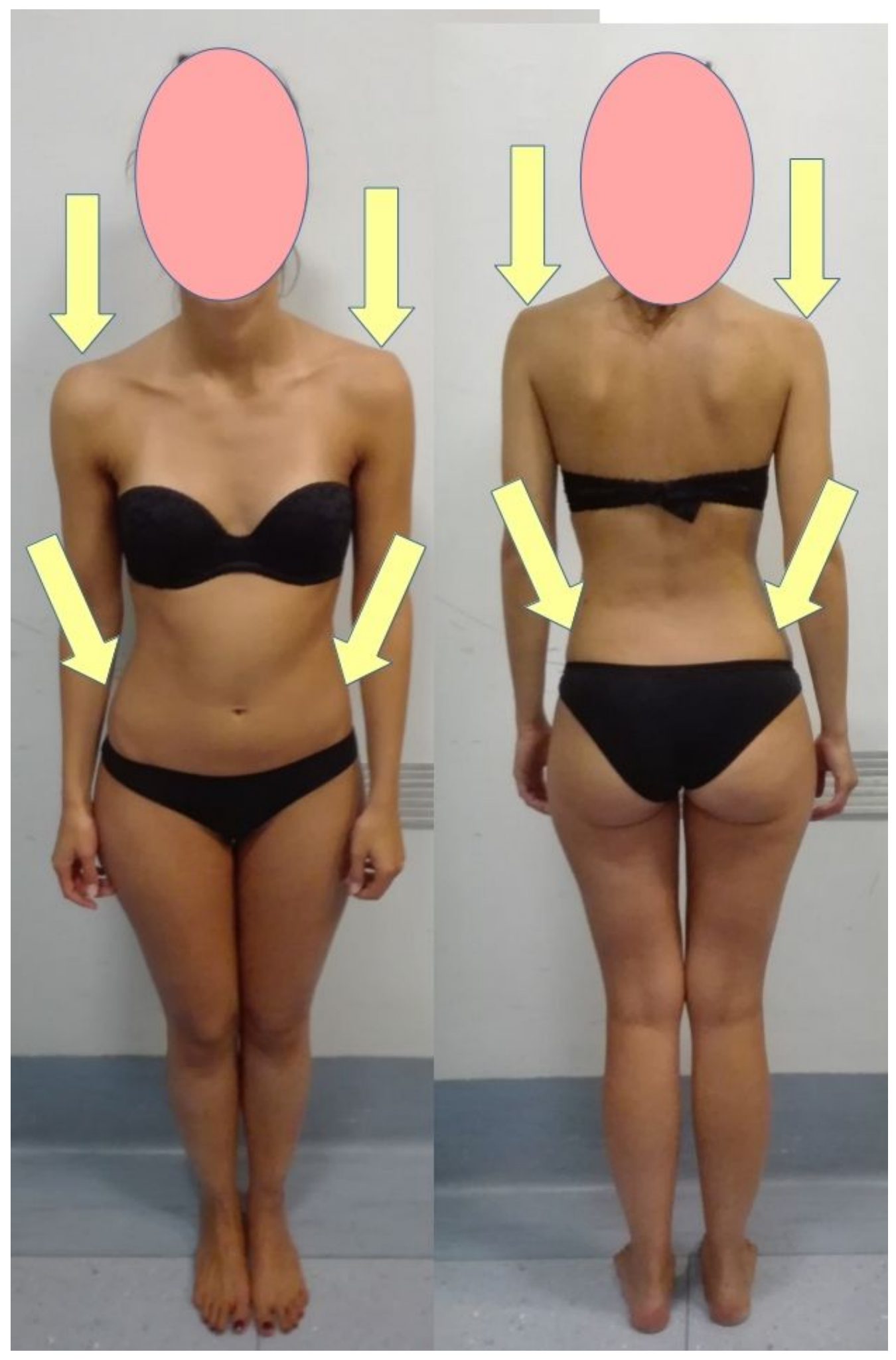

Figure 1

Anatomical reference points 


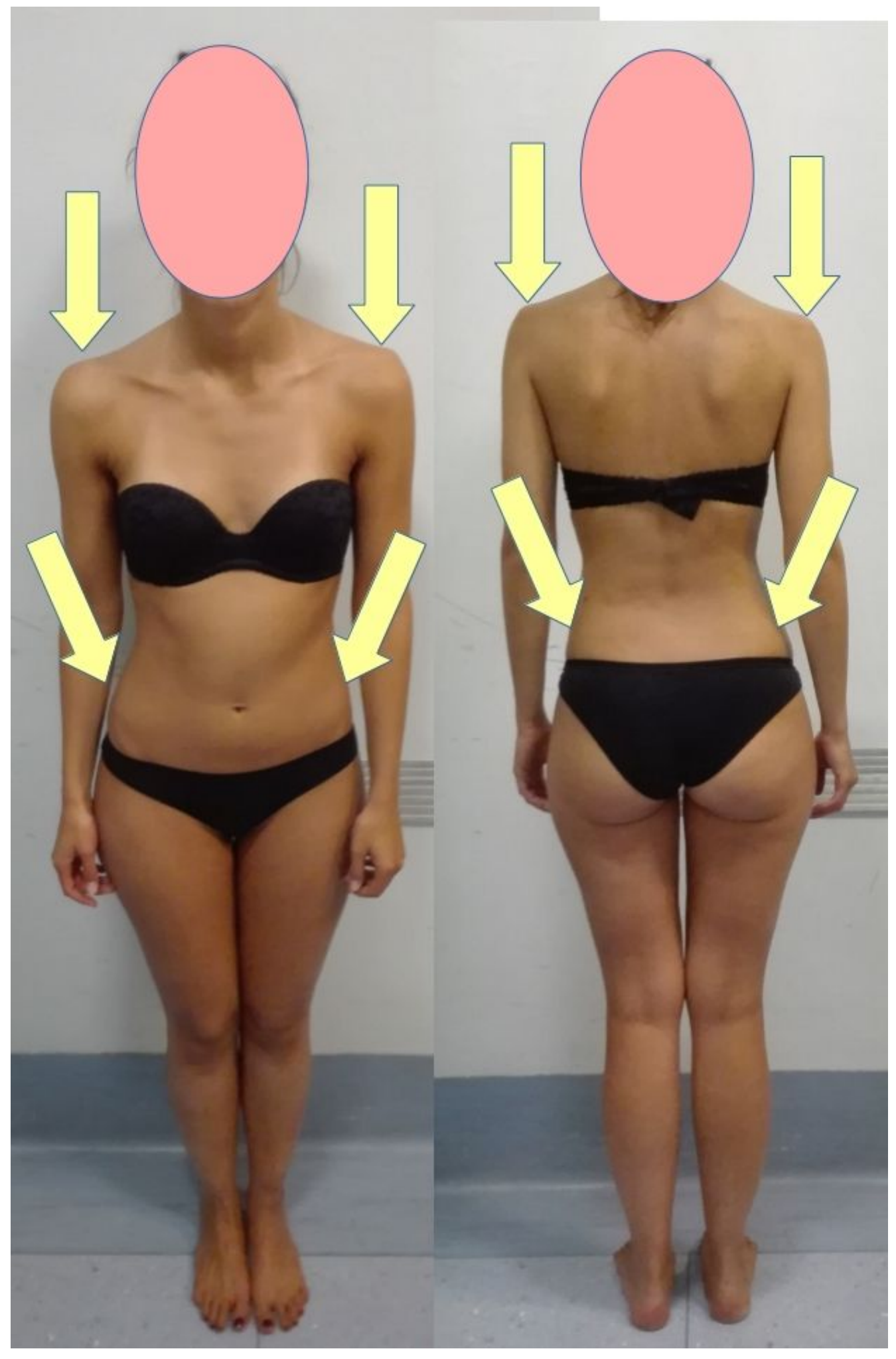

Figure 1

Anatomical reference points 


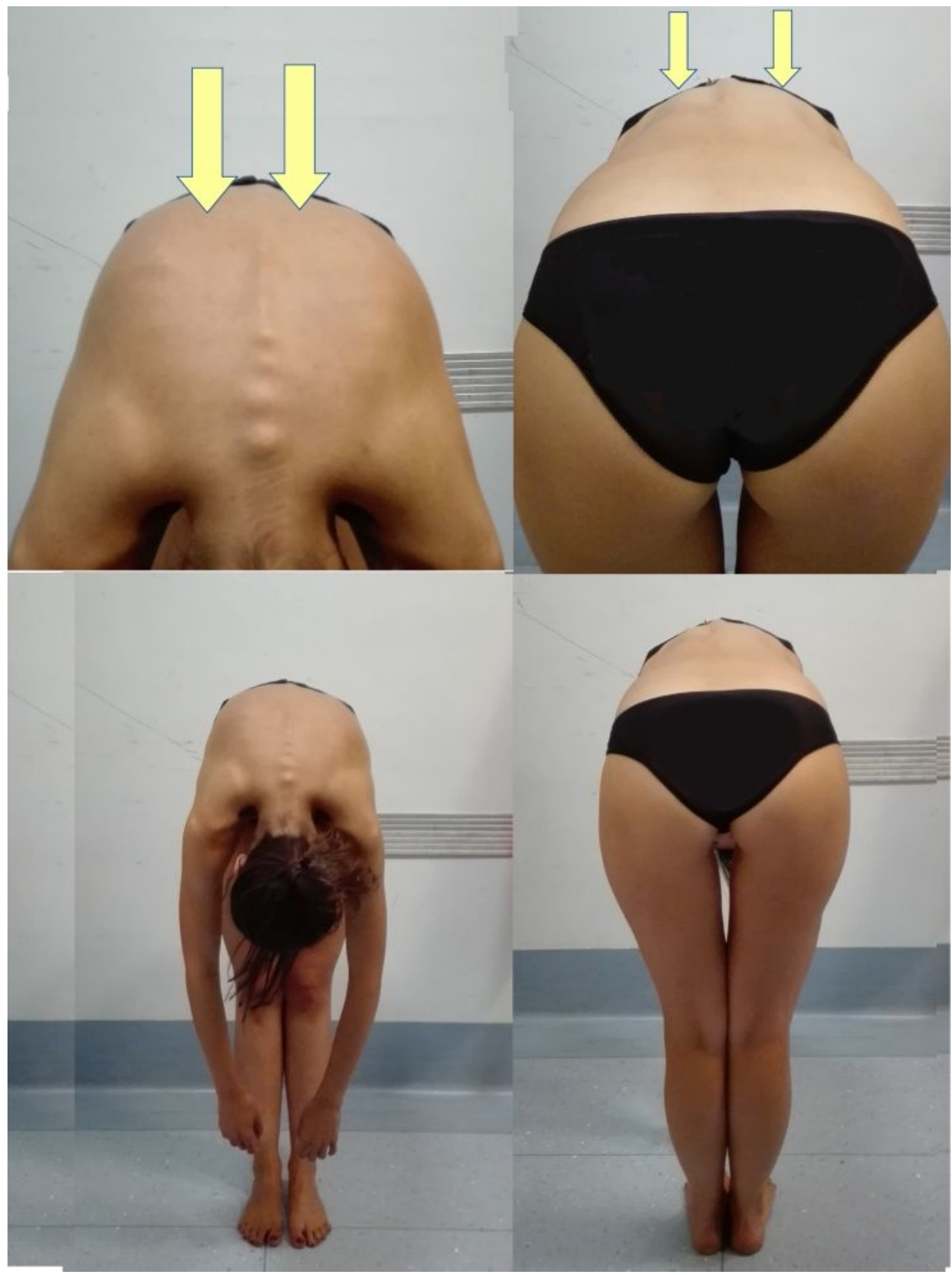

Figure 2

Adam's forward bend test 


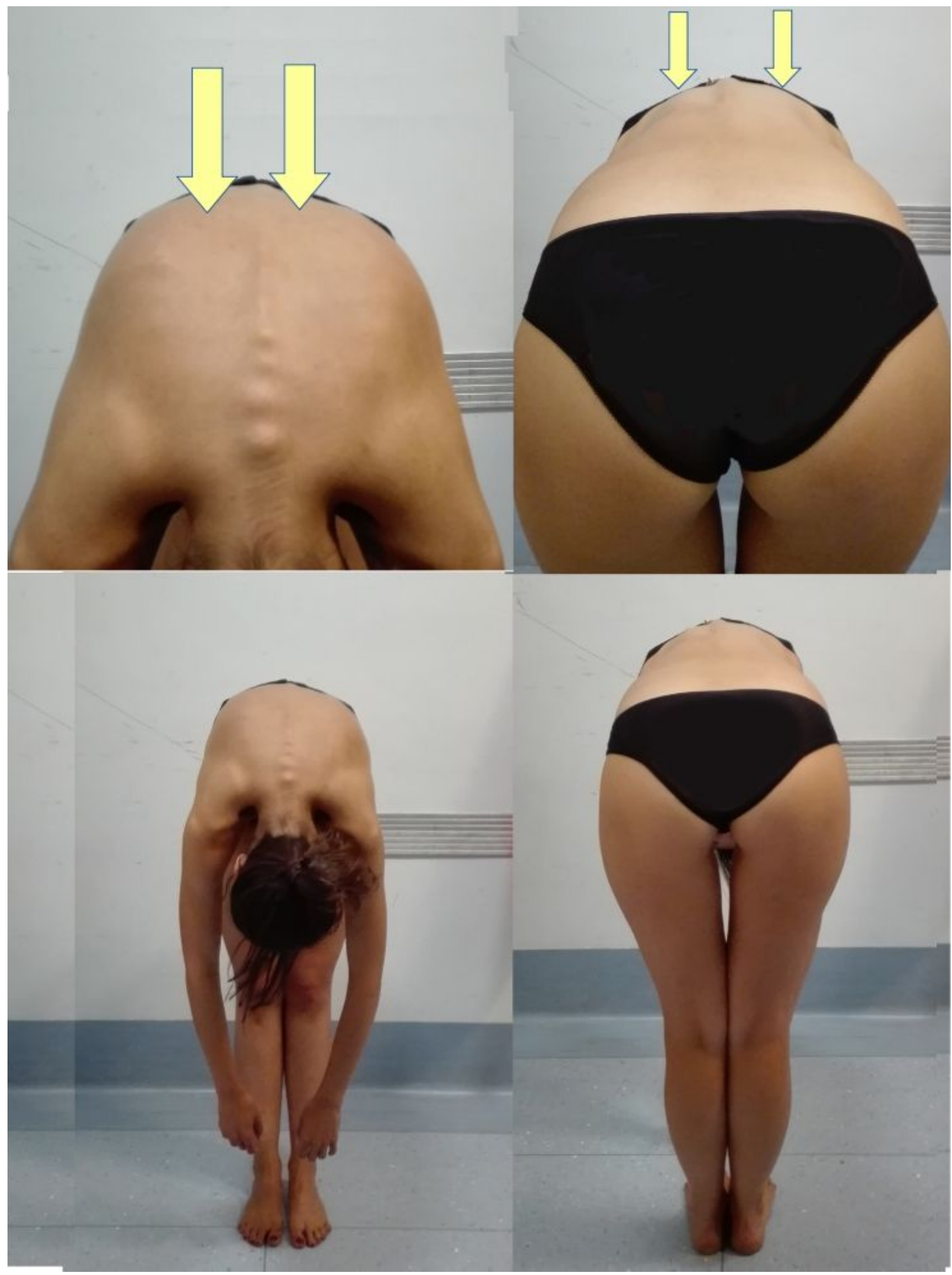

Figure 2

Adam's forward bend test 


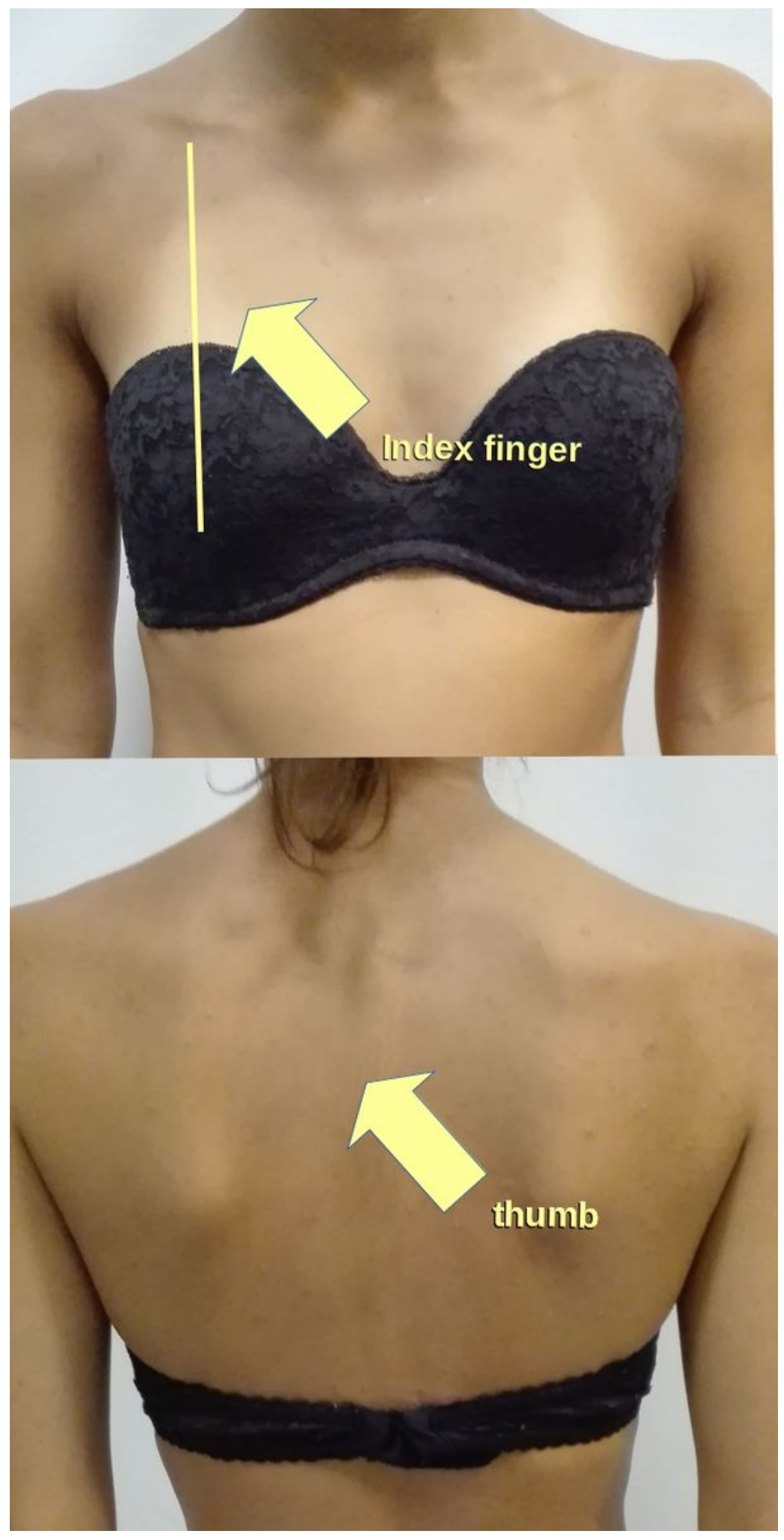

Figure 3

Position of observer's thumb and index finger to clear overlapping between spine and lead cover on mammary glands. 


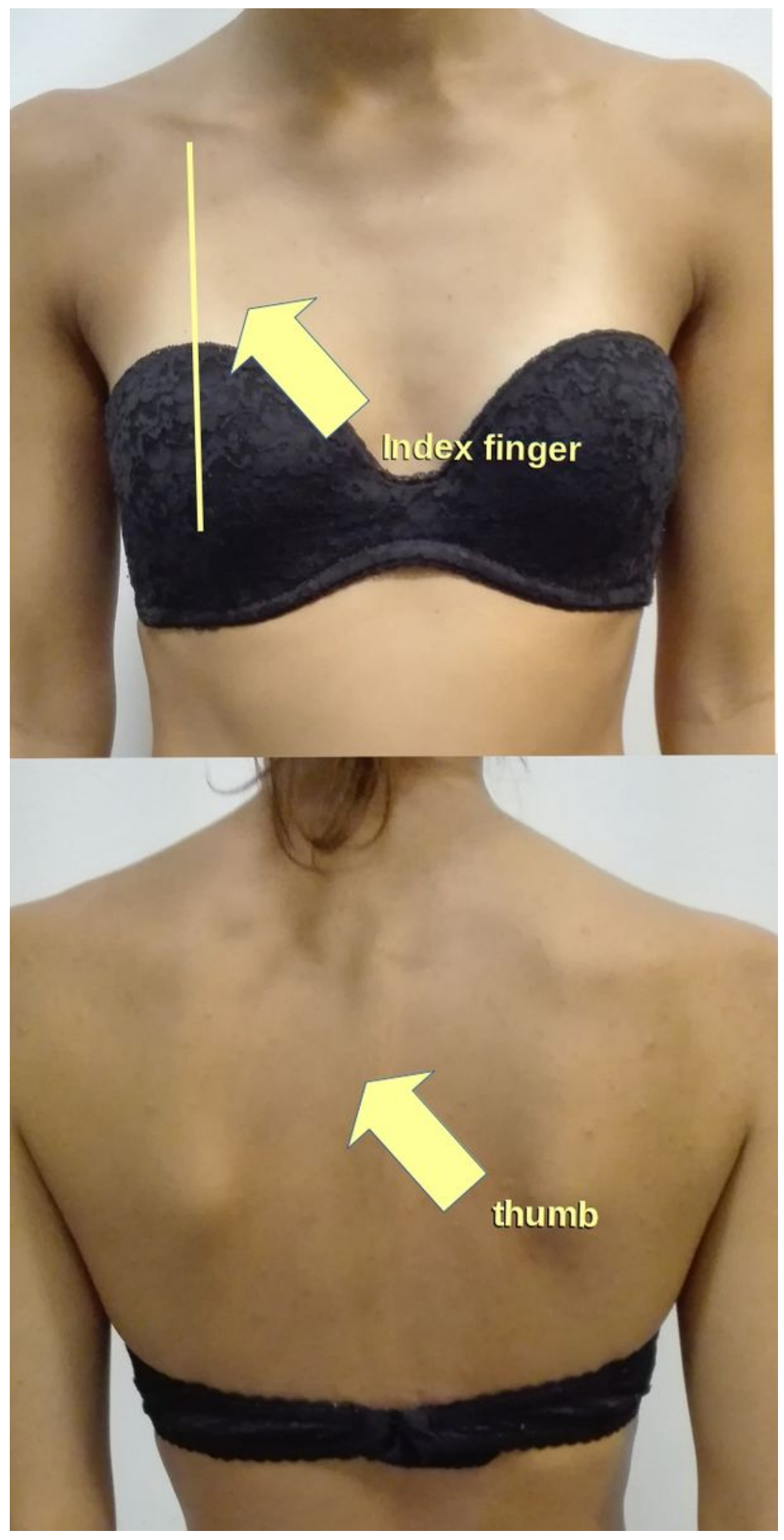

Figure 3

Position of observer's thumb and index finger to clear overlapping between spine and lead cover on mammary glands. 


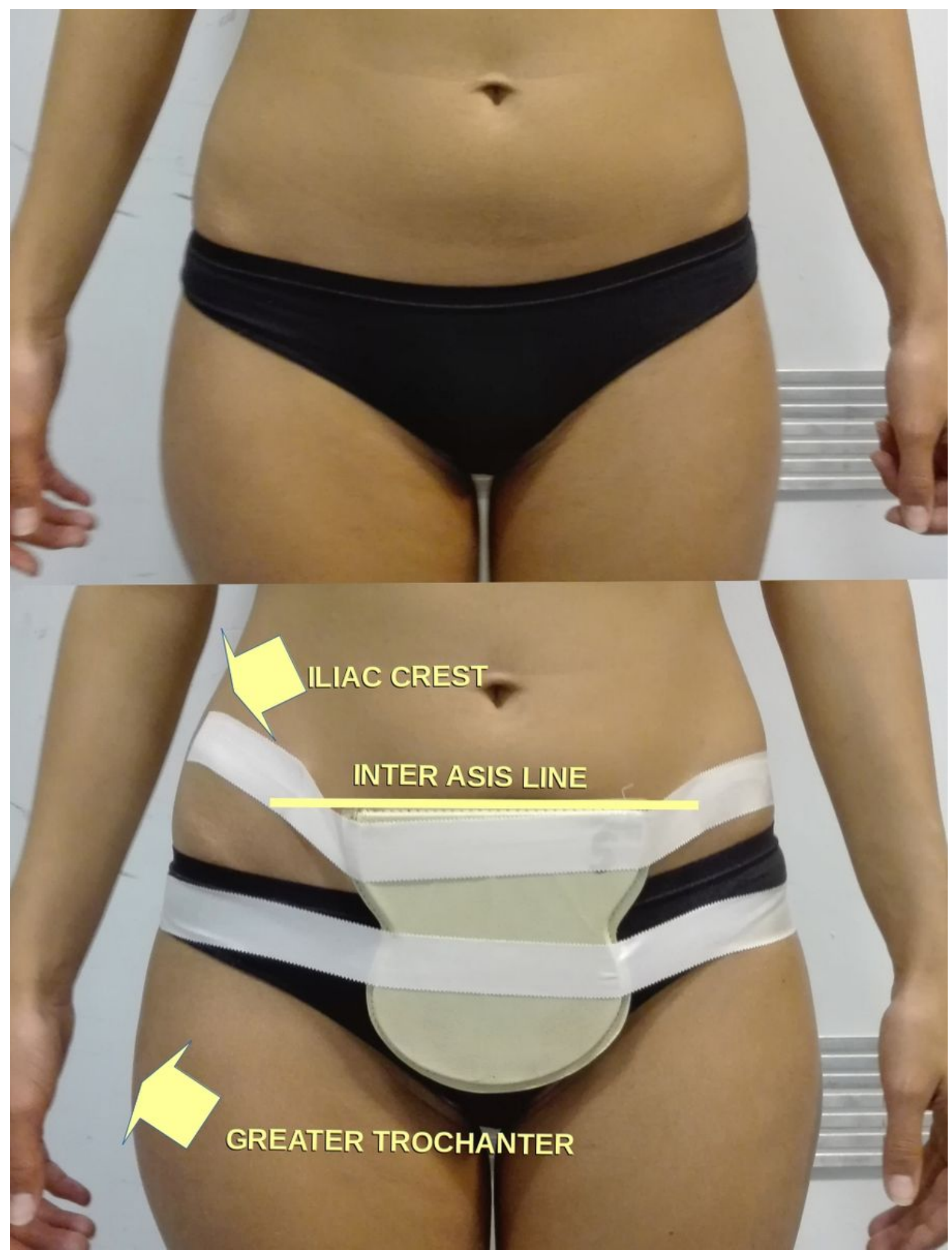

Figure 4

Position of X-ray absorbent shield to protect female genitalia 


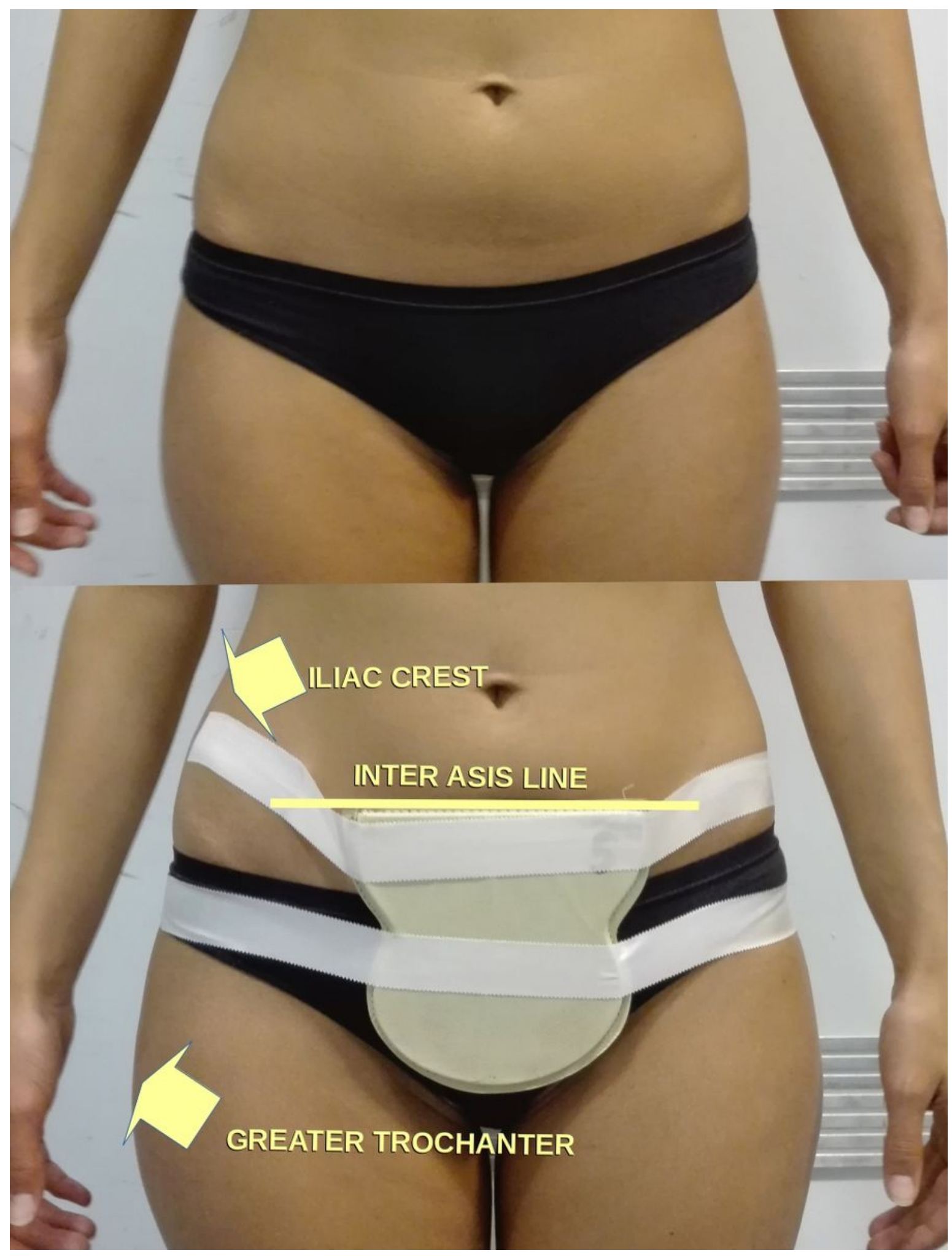

Figure 4

Position of X-ray absorbent shield to protect female genitalia 


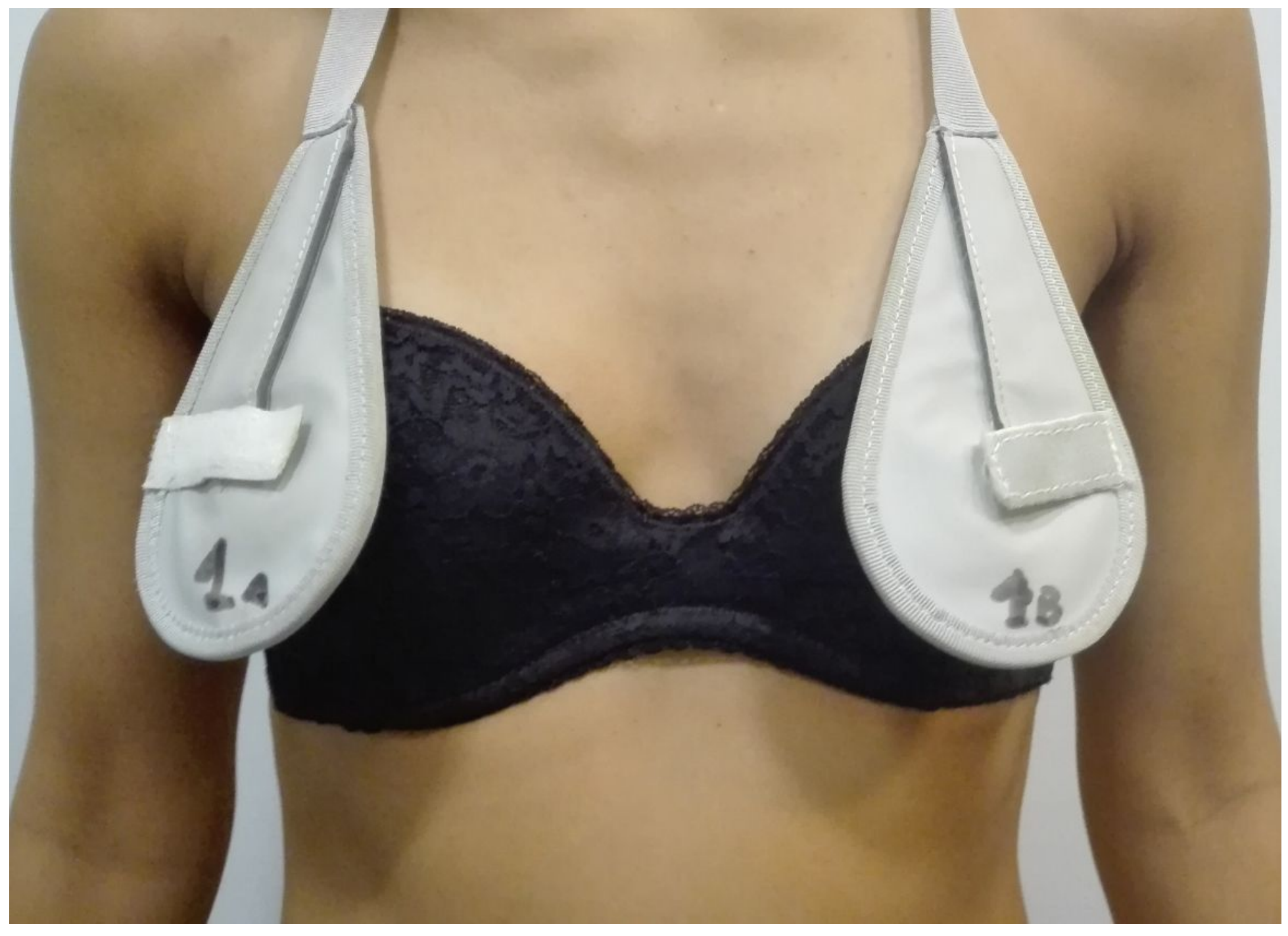

Figure 5

Position of X-ray adsorbent shields to protect the breast 


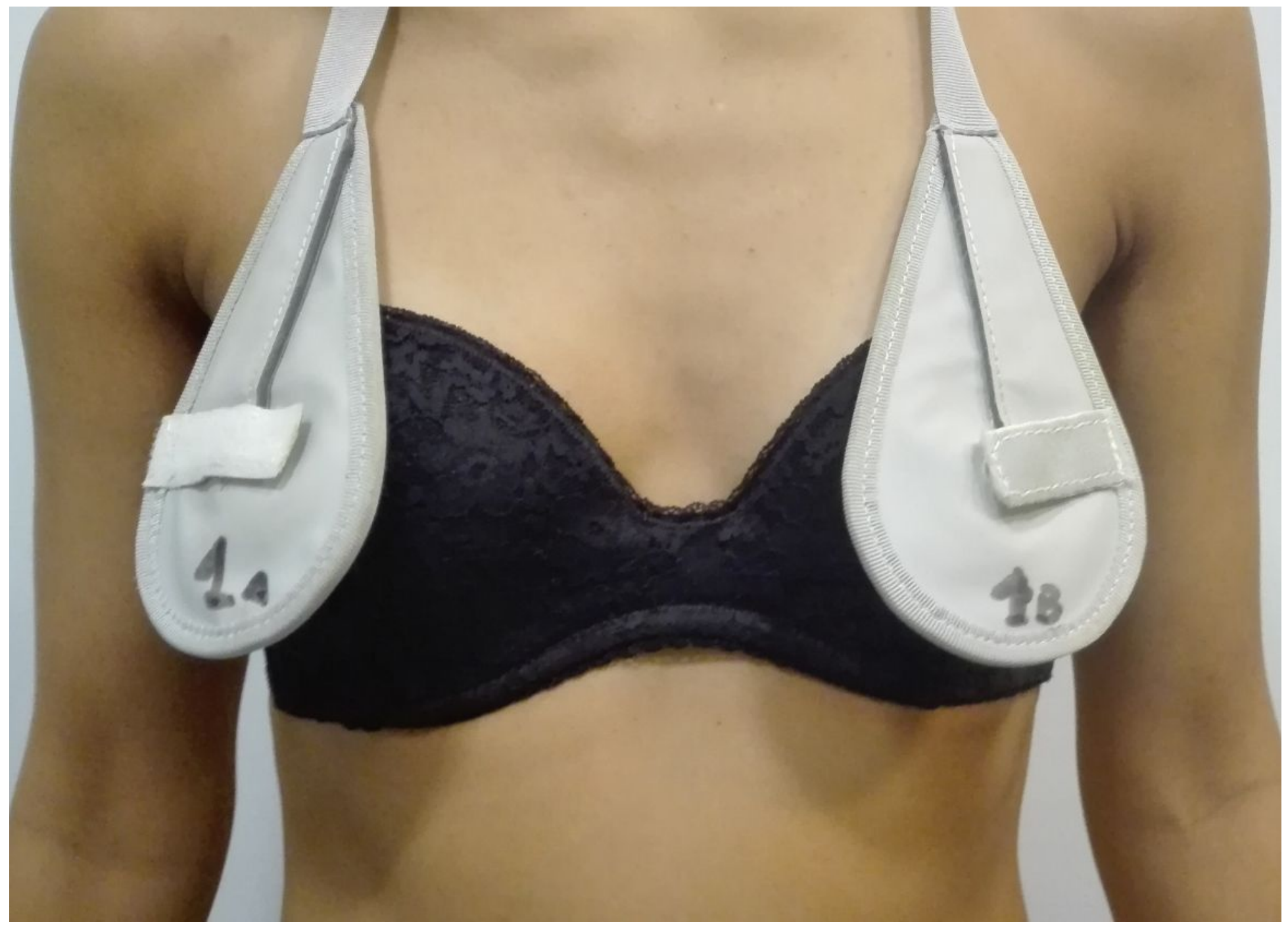

Figure 5

Position of X-ray adsorbent shields to protect the breast

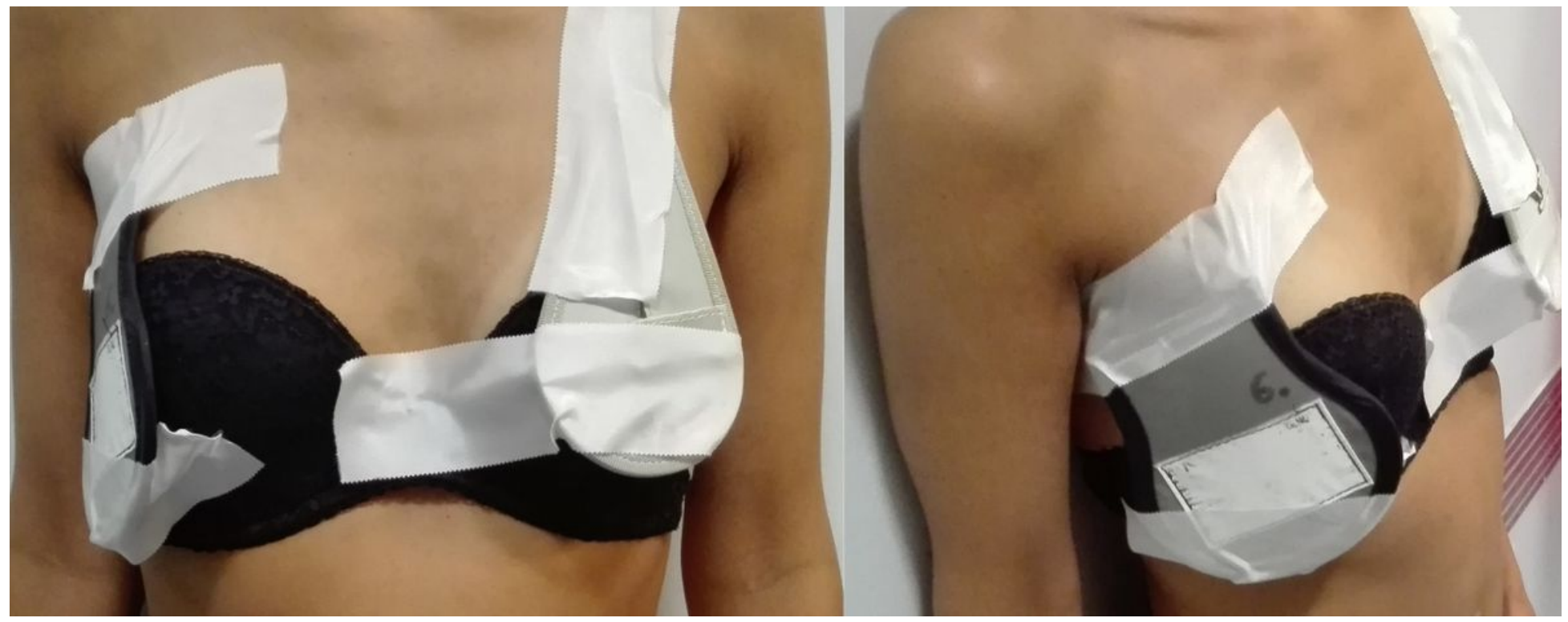

Figure 6 


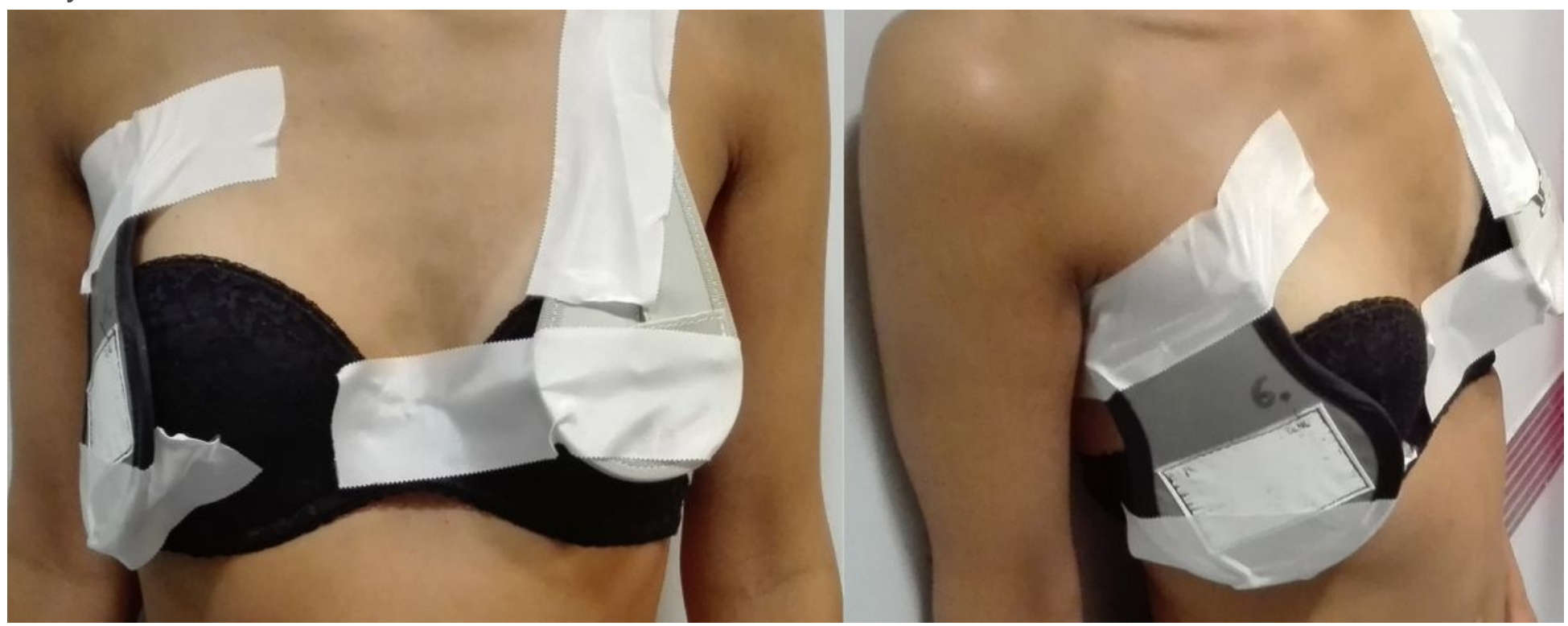

Figure 6

X-ray breast shields in severe toracic curve
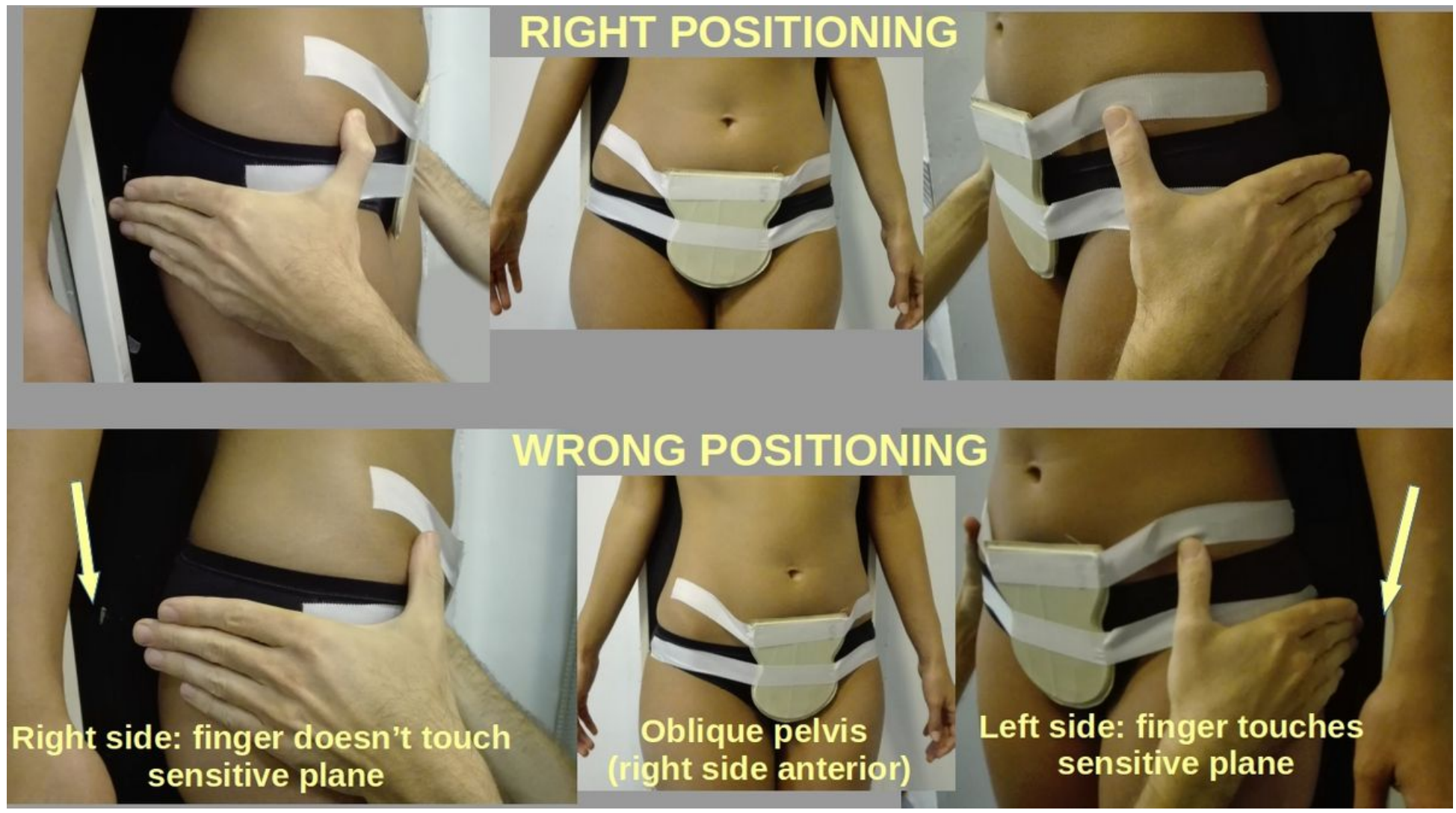

\section{Figure 7}

AP view pelvis positioning 

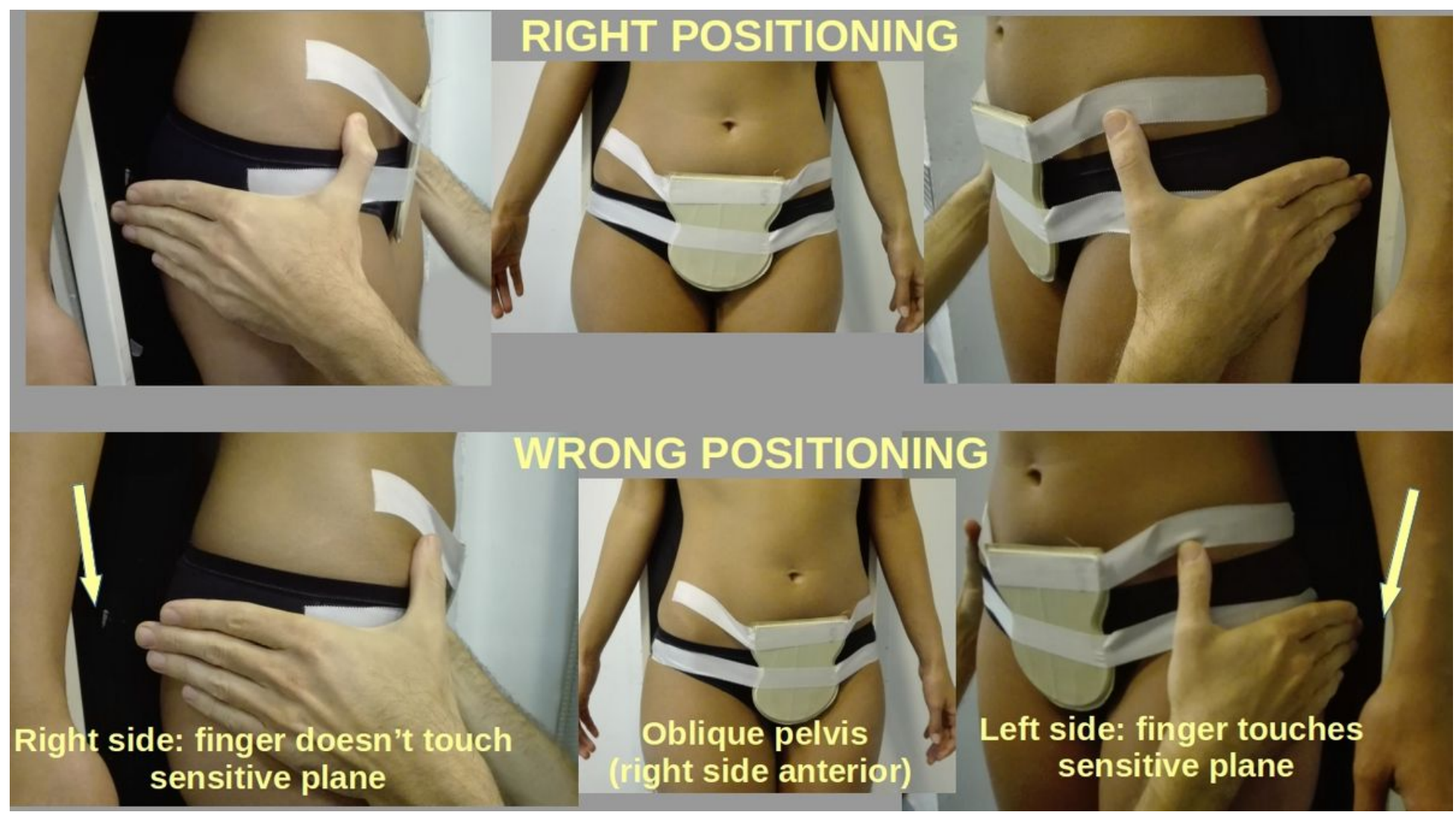

\section{Figure 7}

AP view pelvis positioning 


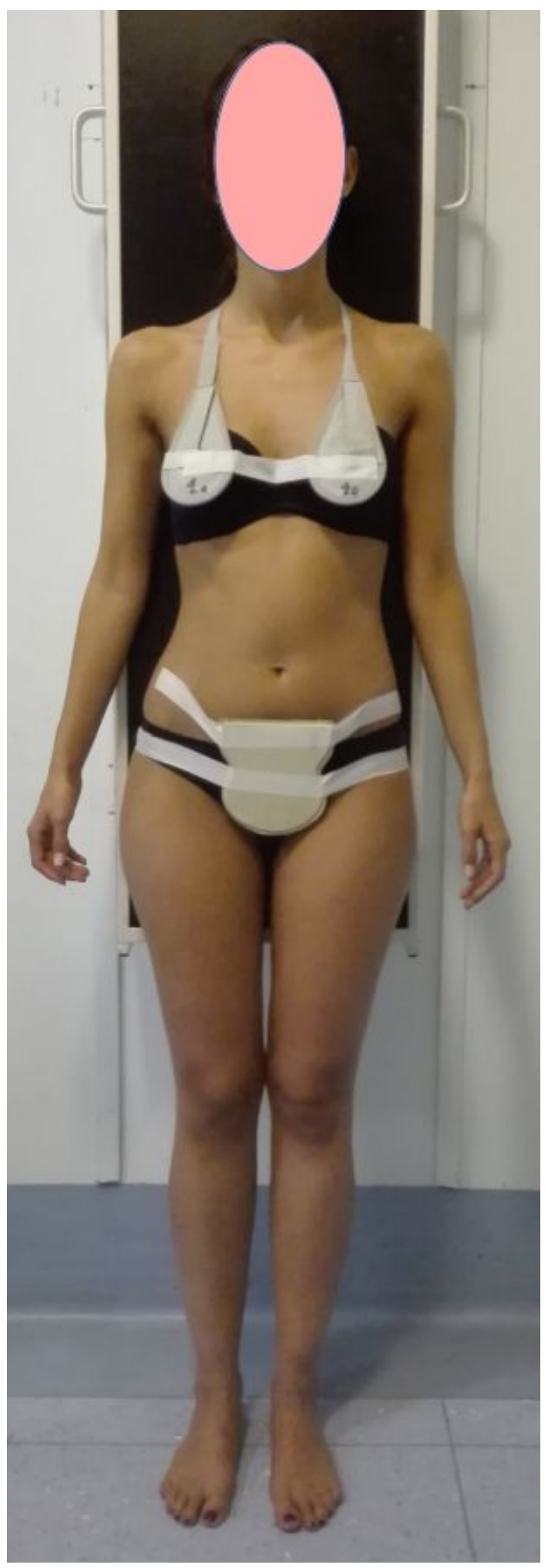

Figure 8

AP view positioning 


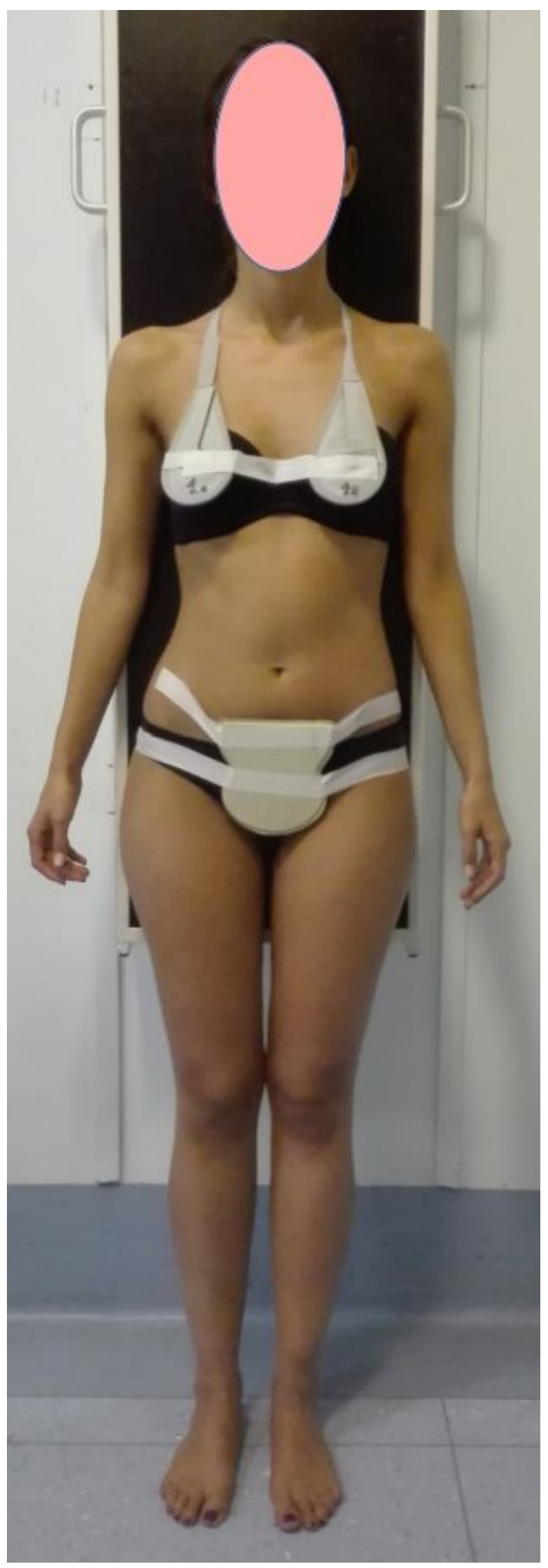

Figure 8

AP view positioning 


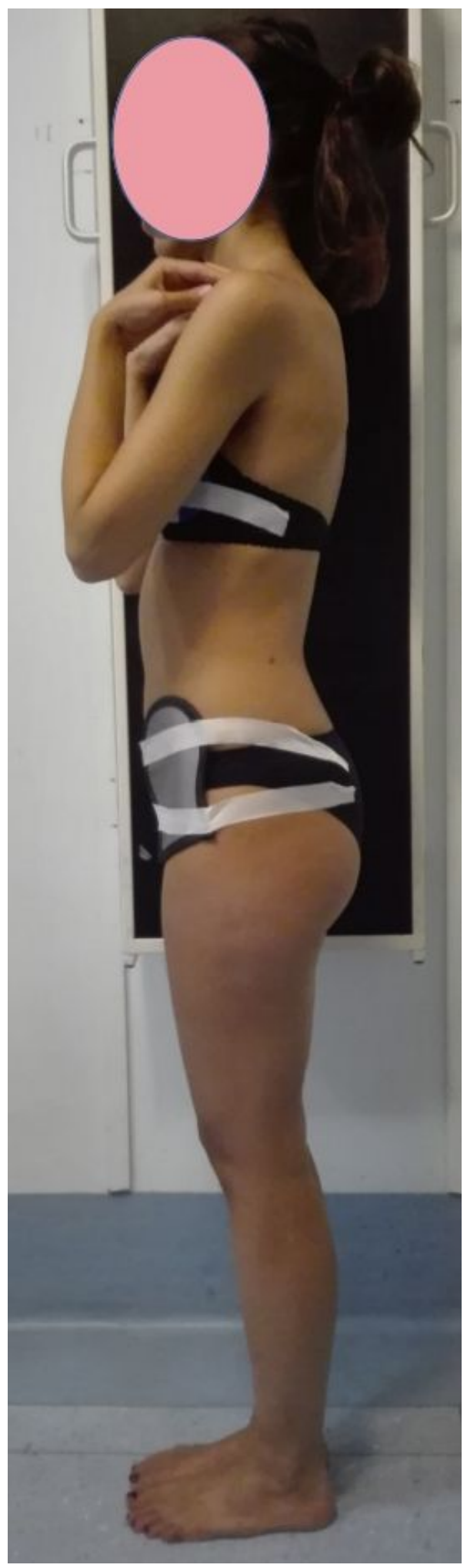

Figure 9

LL view positioning 


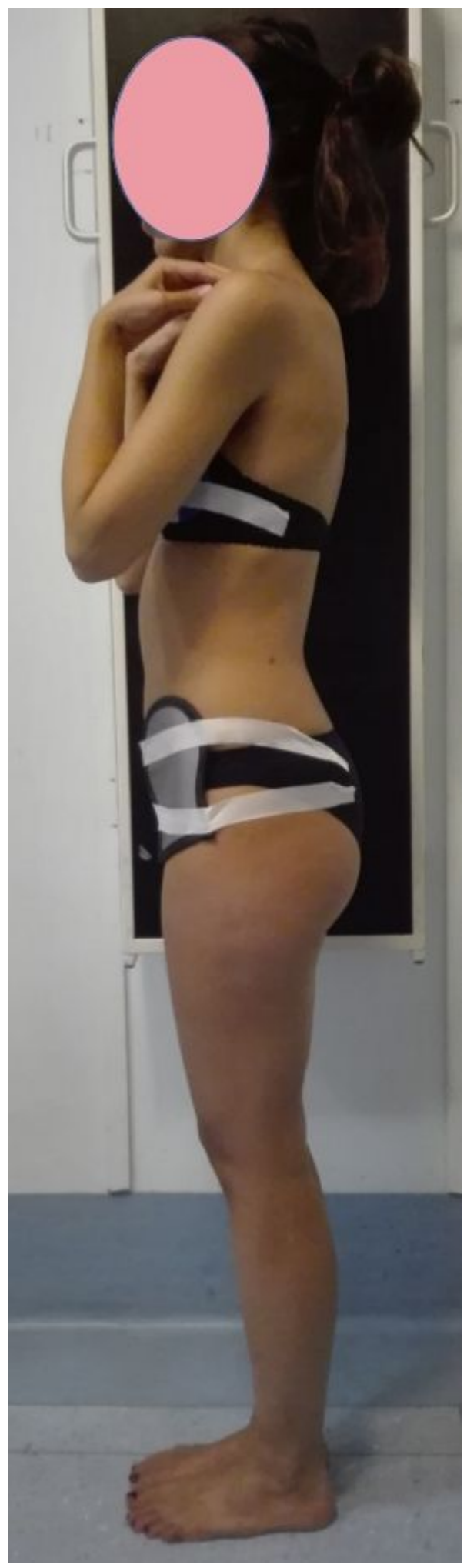

Figure 9

LL view positioning 


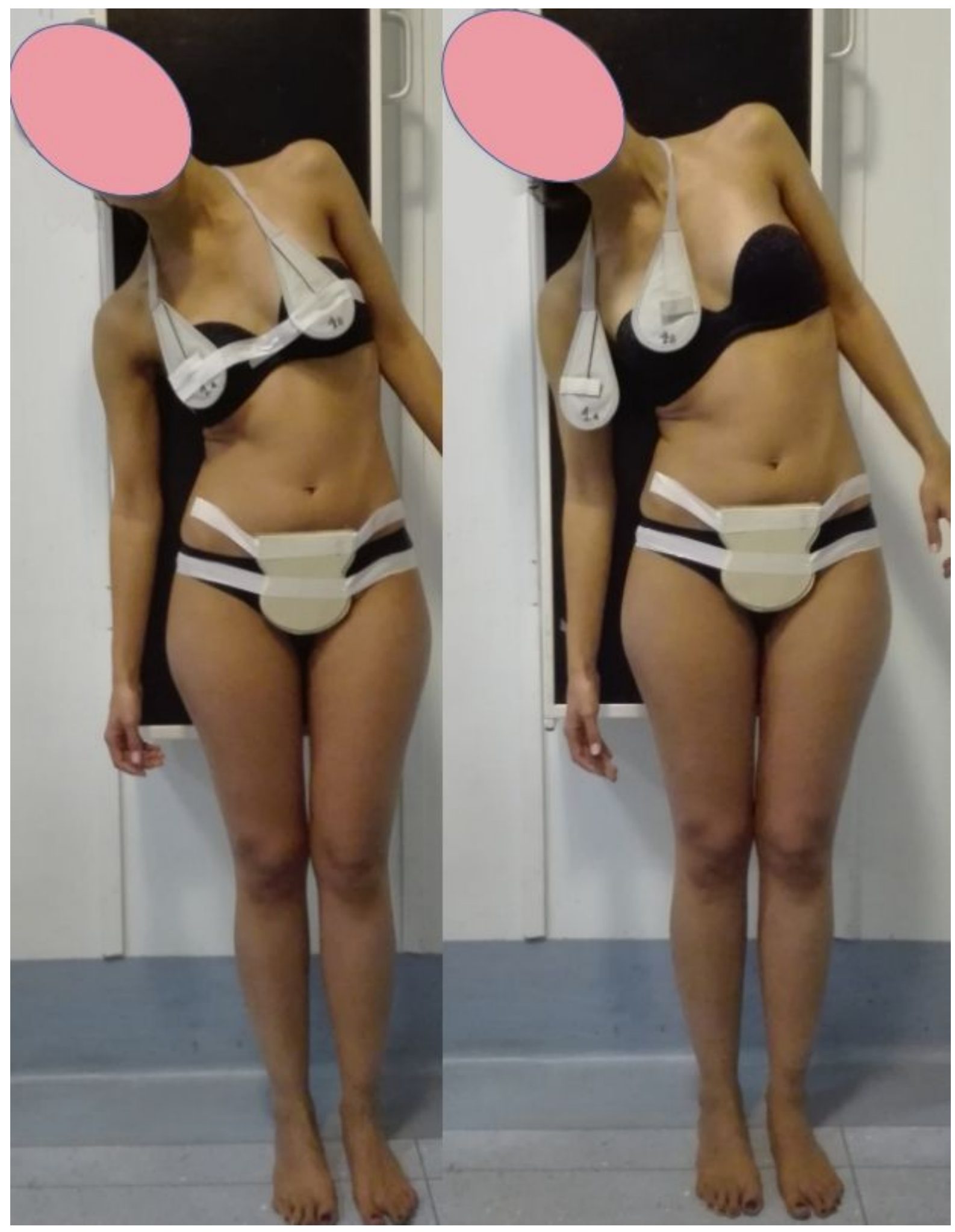

Figure 10

Bending view positioning: correct (left) and wrong (right) 


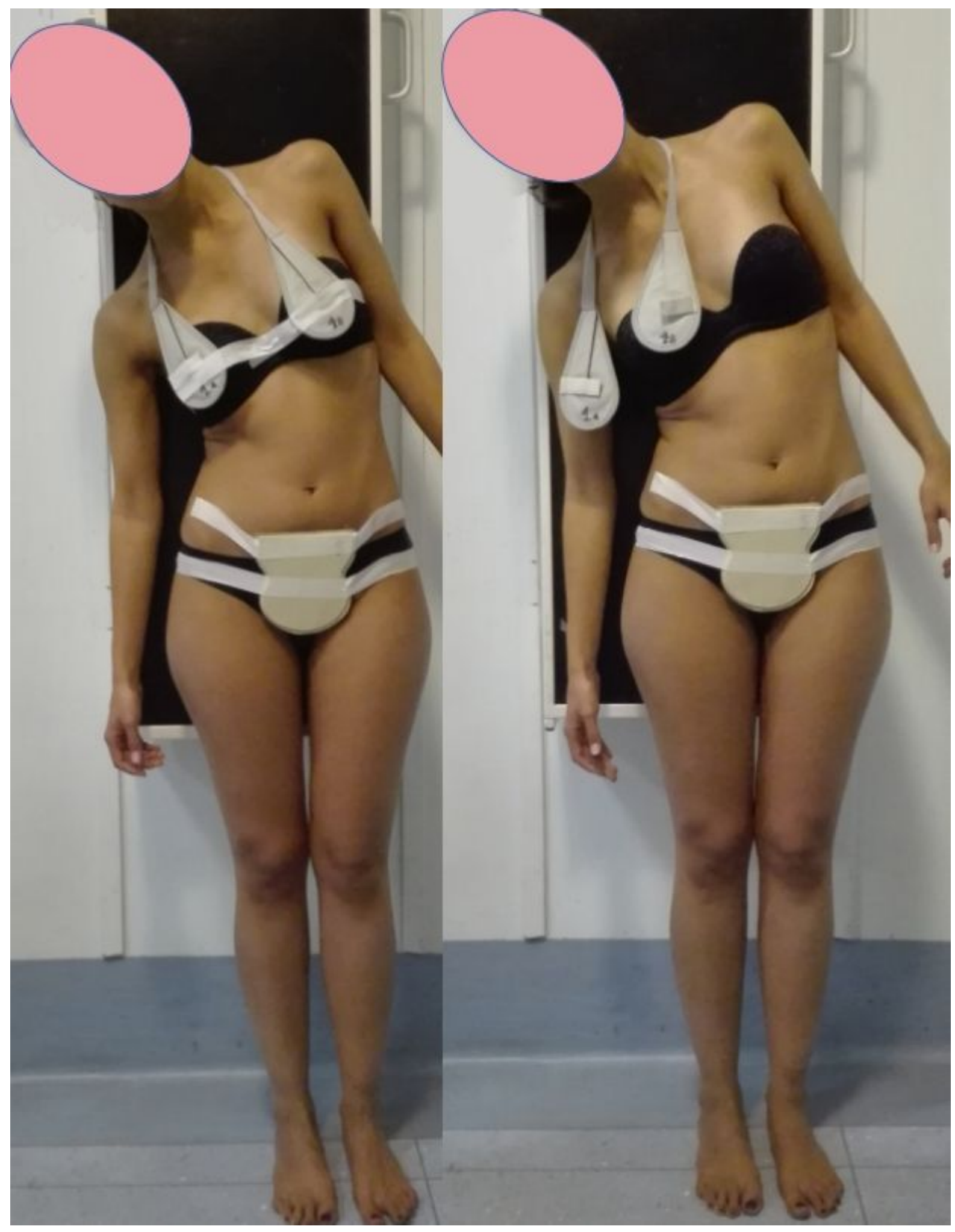

Figure 10

Bending view positioning: correct (left) and wrong (right) 


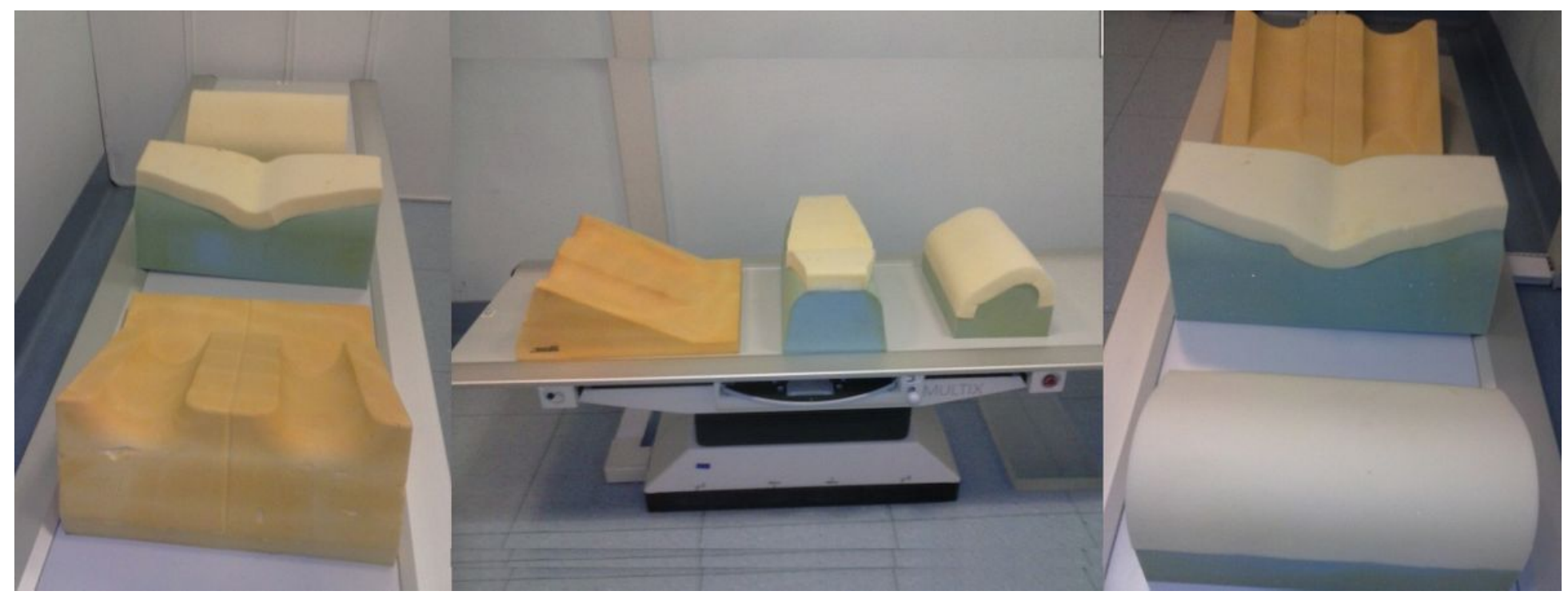

Figure 11

\section{Supports}

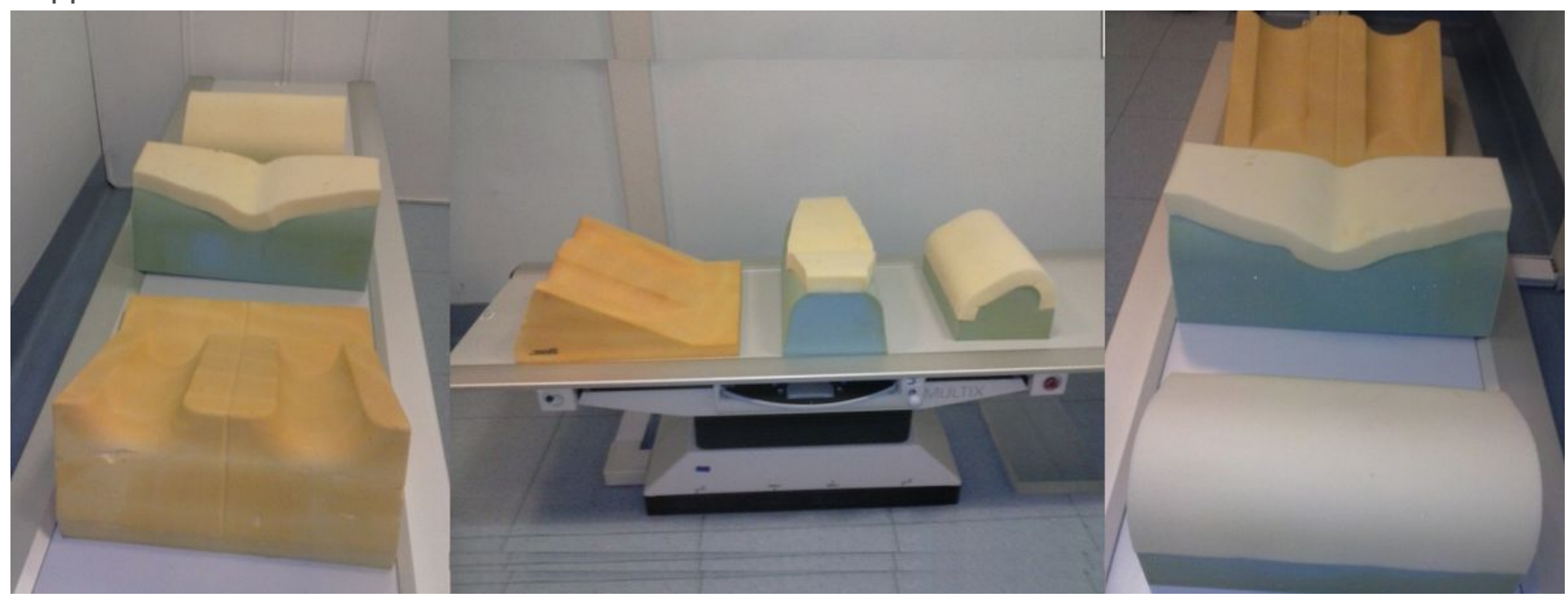

Figure 11

Supports 


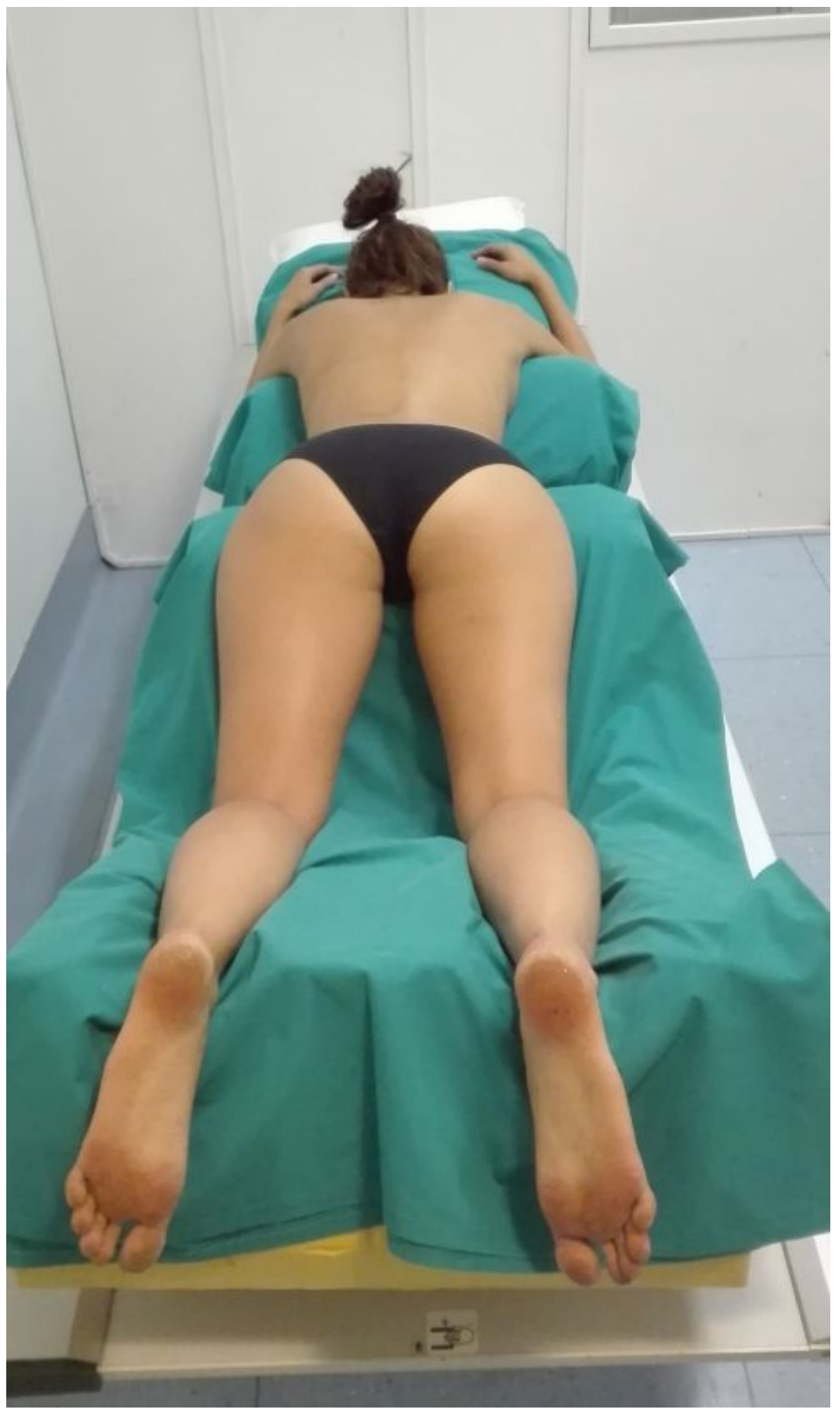

Figure 12

Prone positioning 


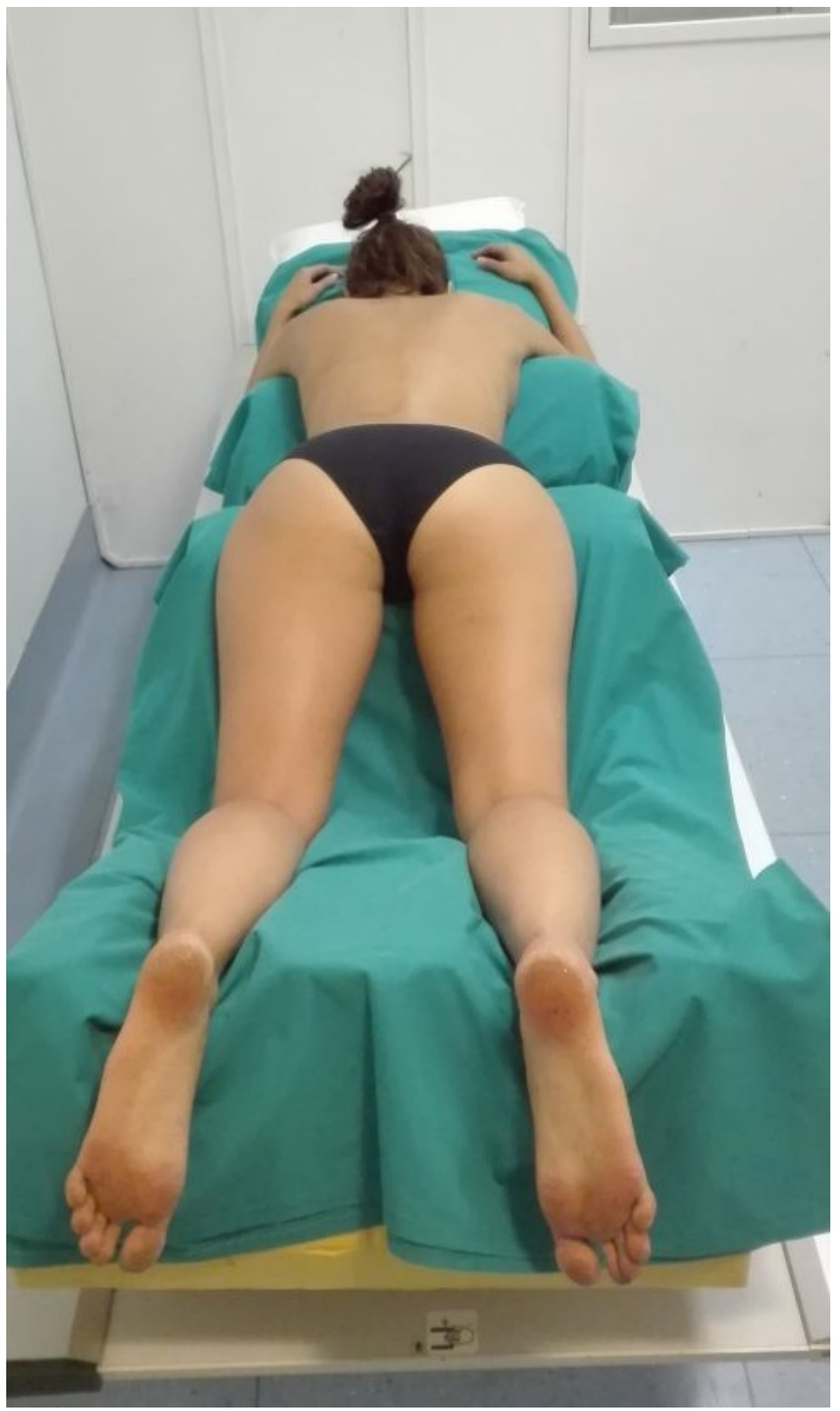

Figure 12

Prone positioning 


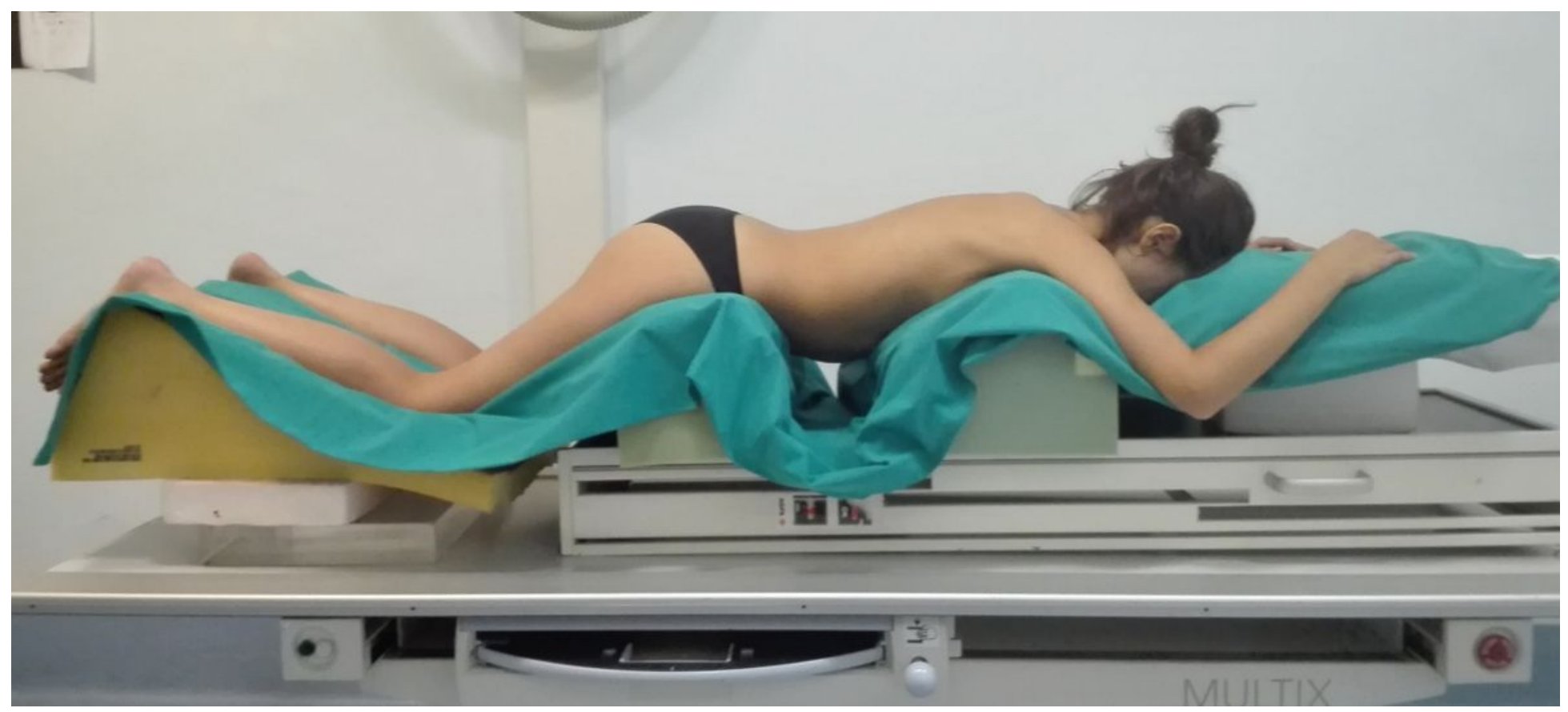

Figure 13

Prone positioning

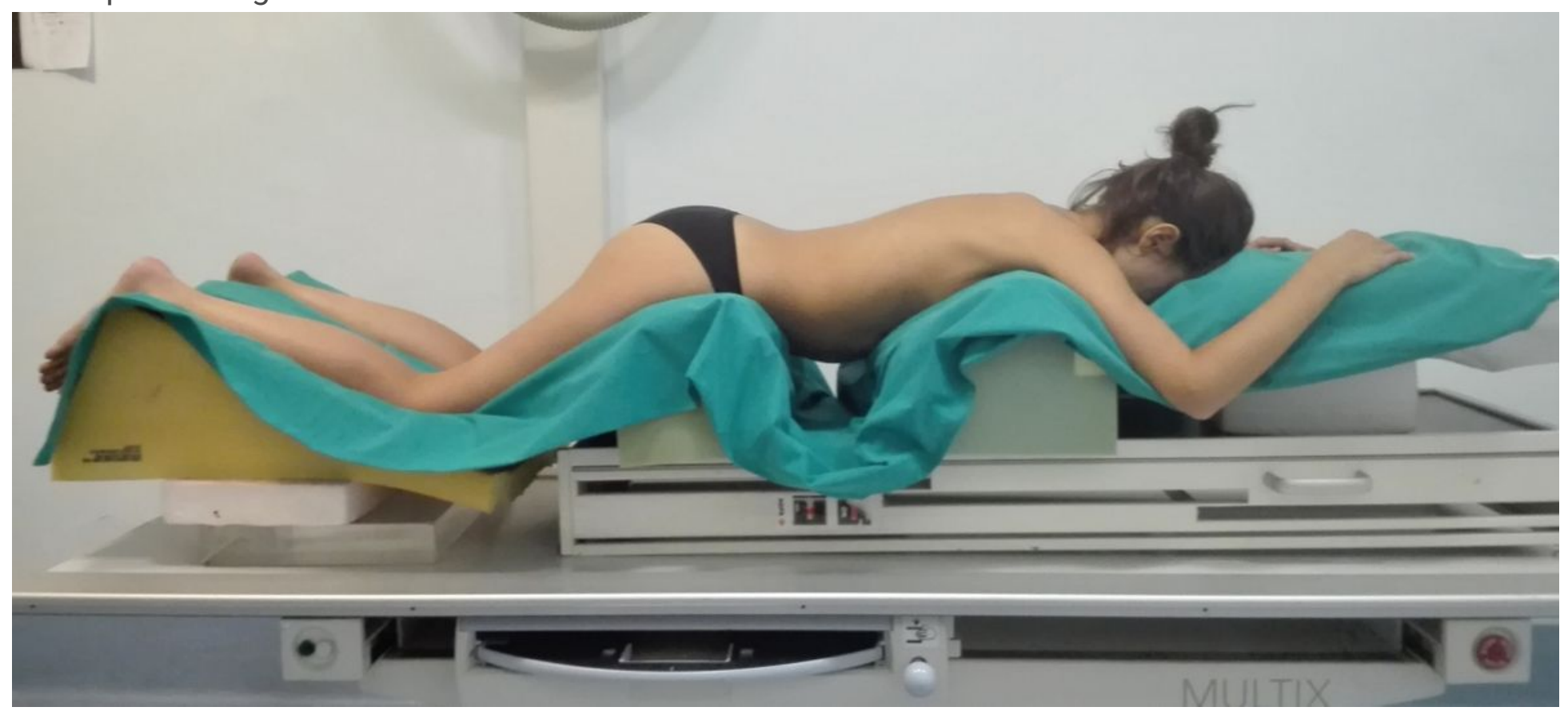

Figure 13

Prone positioning 


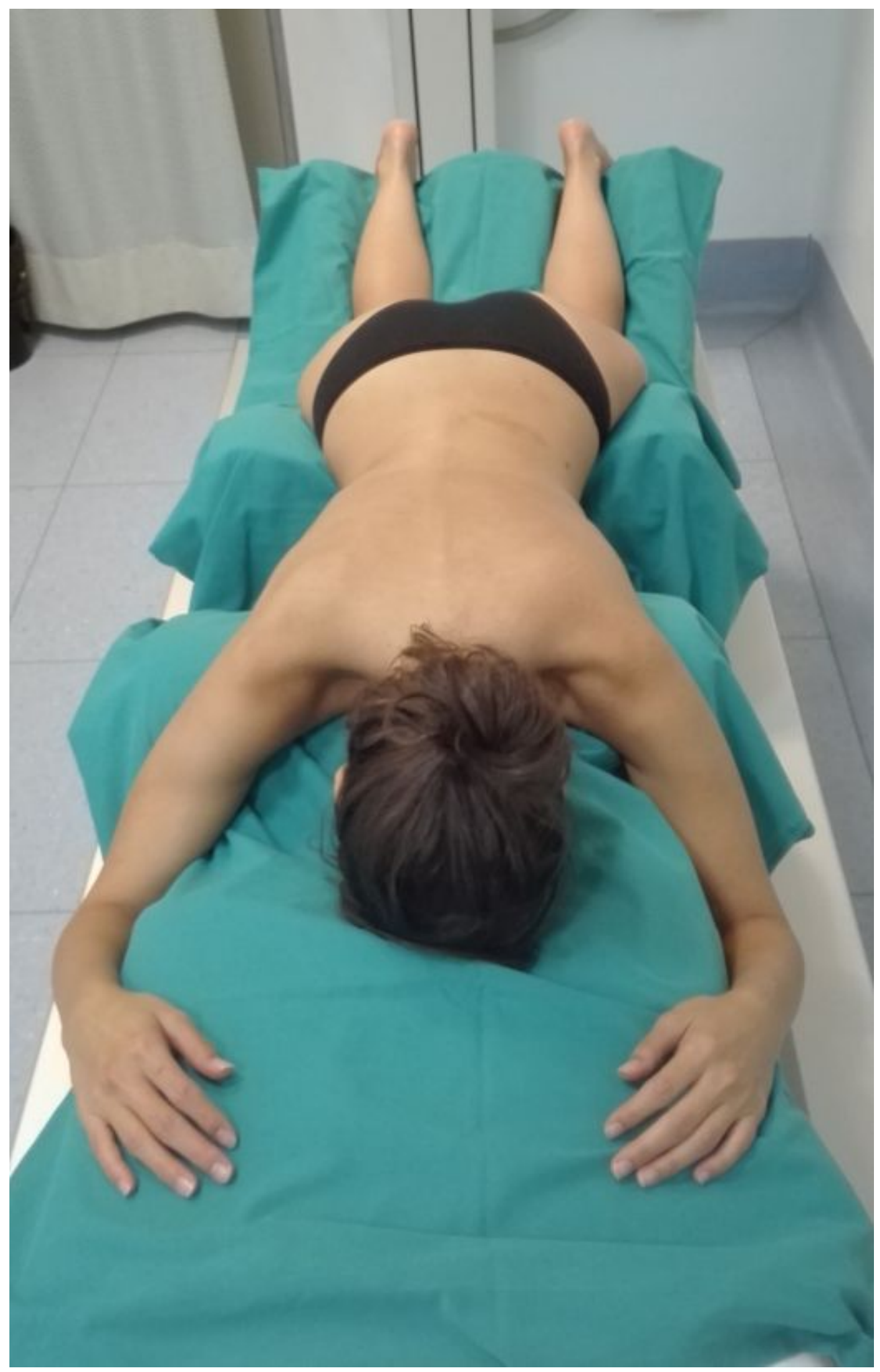

Figure 14

Prone positioning 


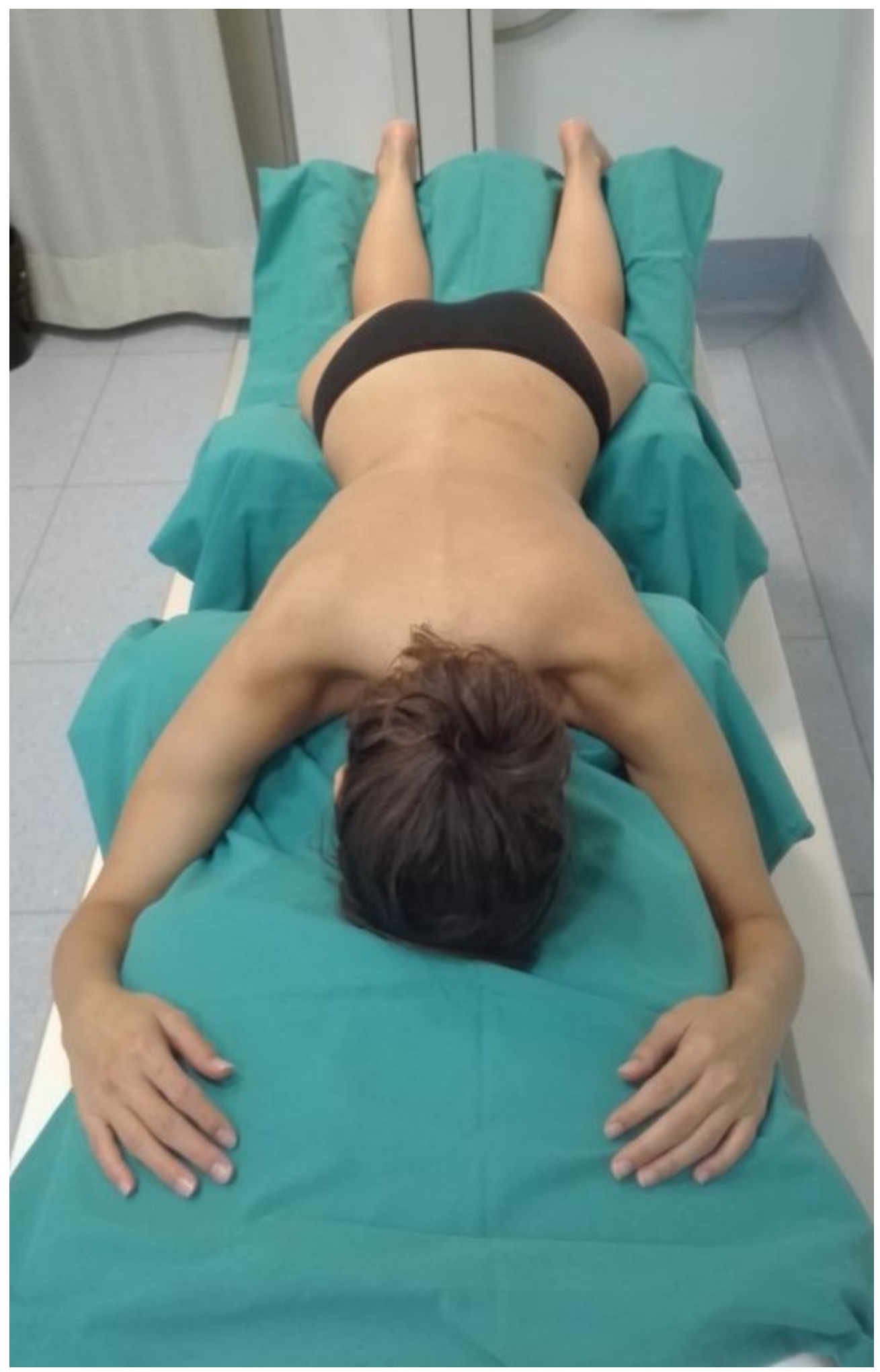

Figure 14

Prone positioning 


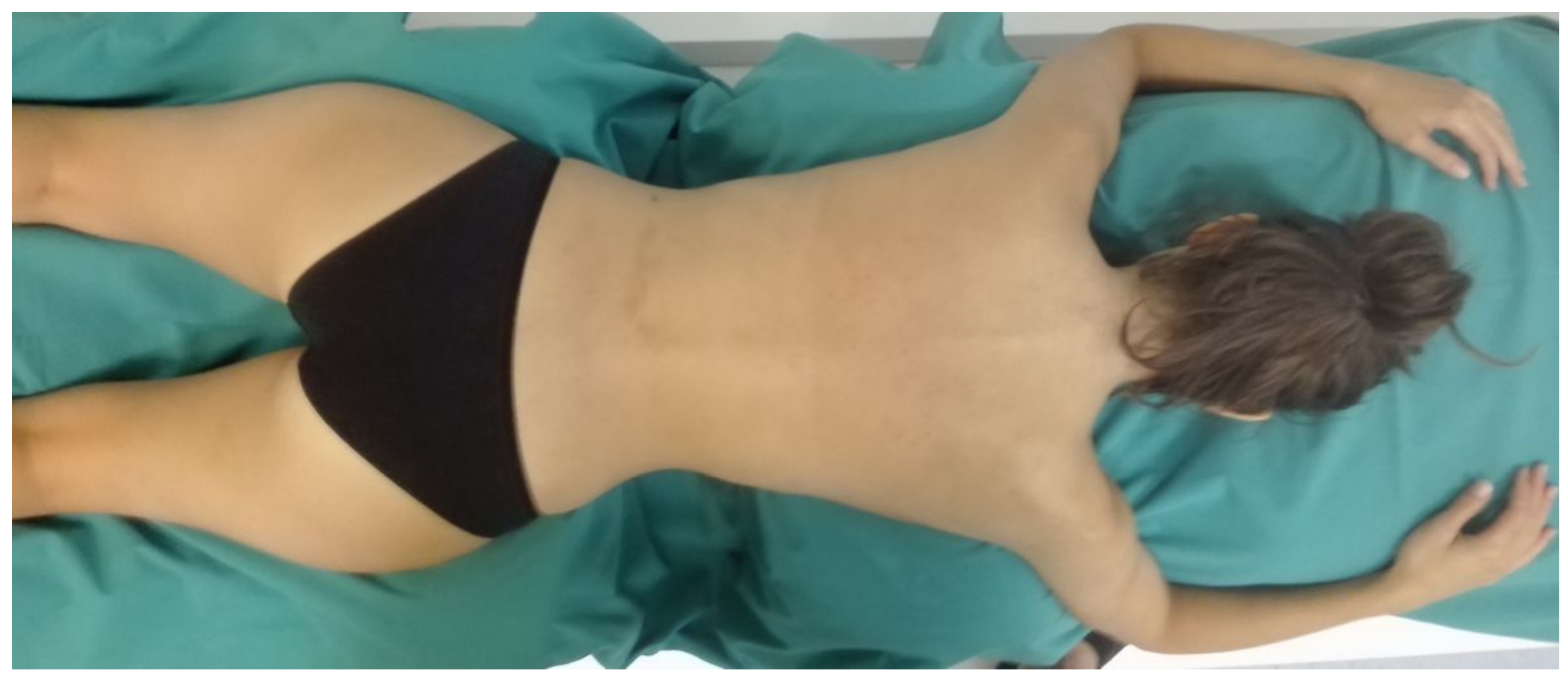

Figure 15

\section{Prone positioning}

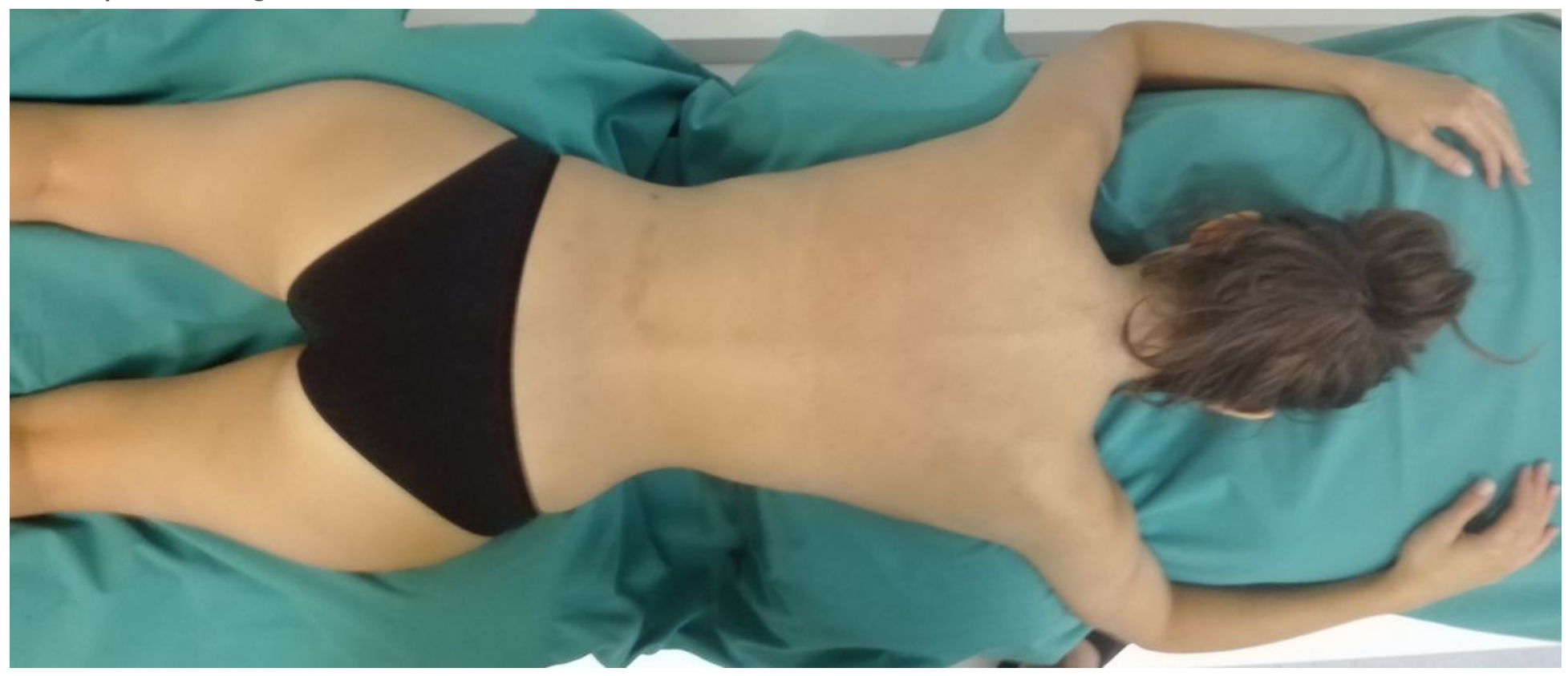

Figure 15

Prone positioning 


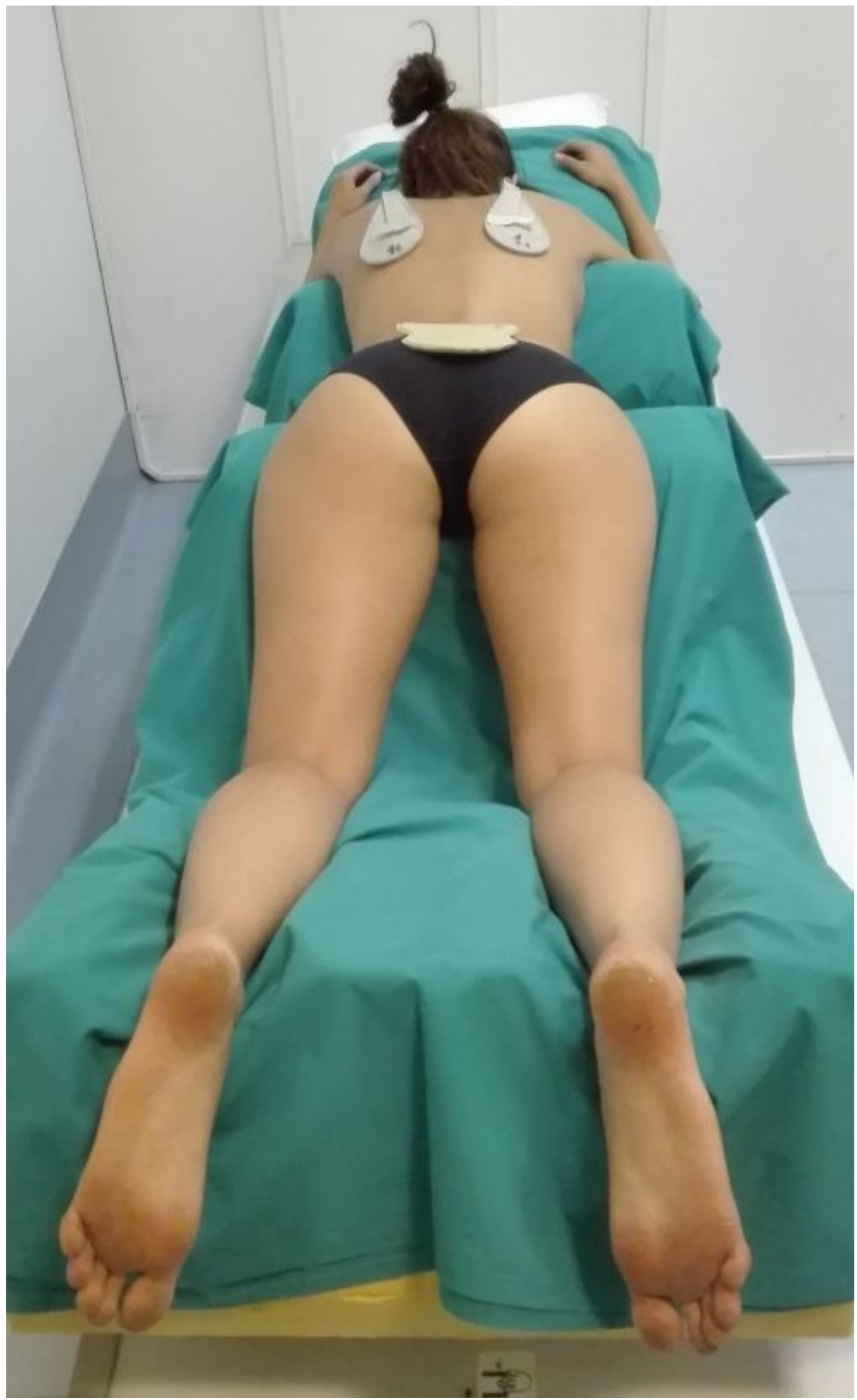

Figure 16

Prone positioning 


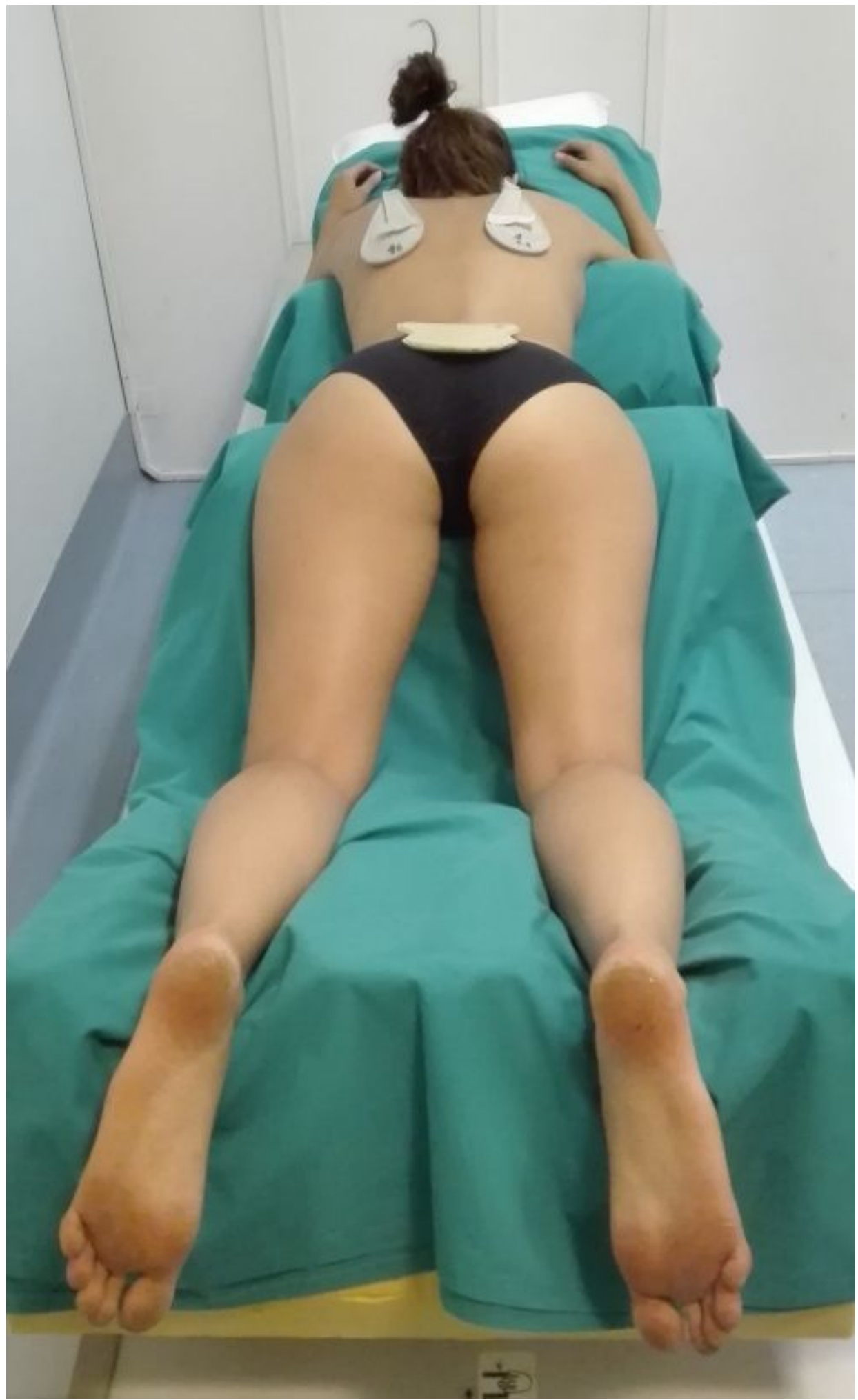

Figure 16

Prone positioning 


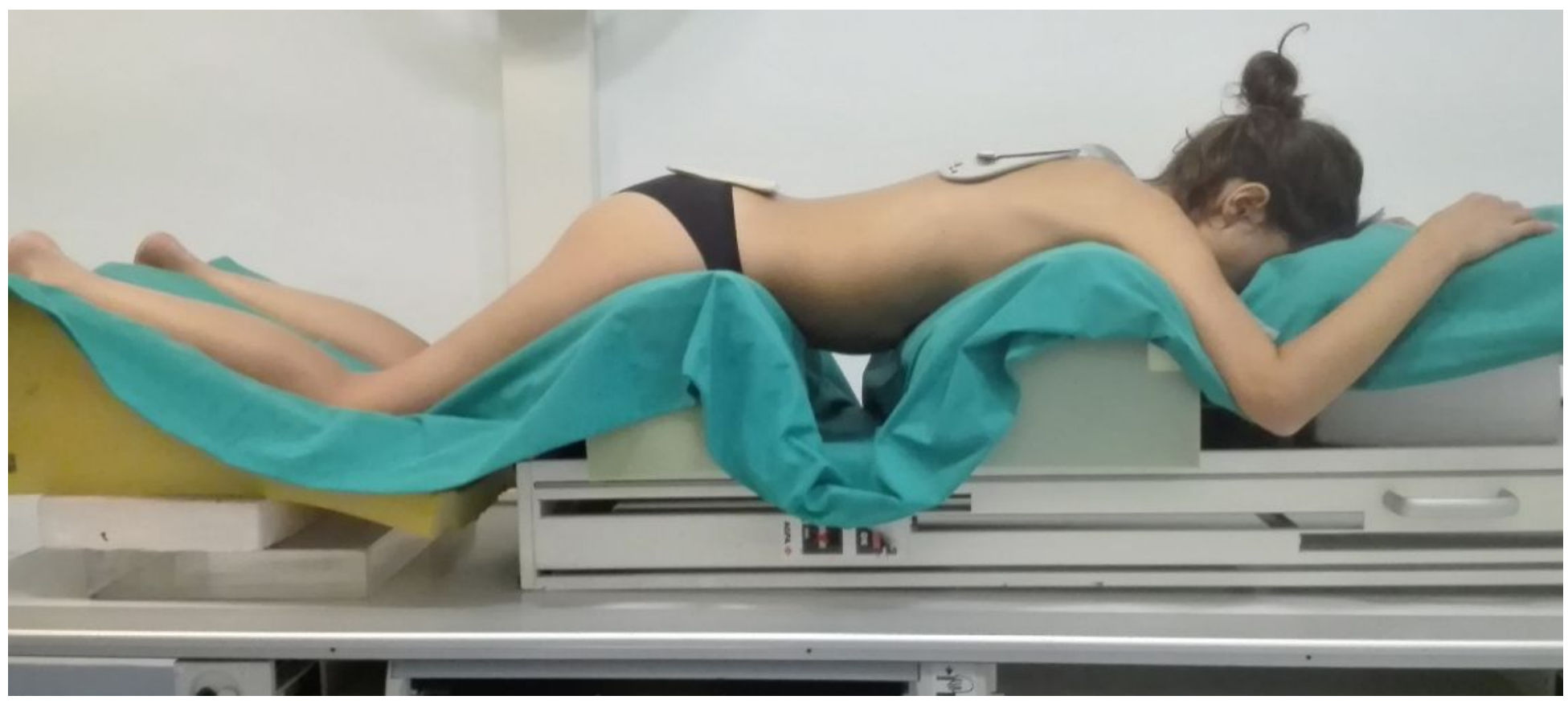

Figure 17

Prone positioning

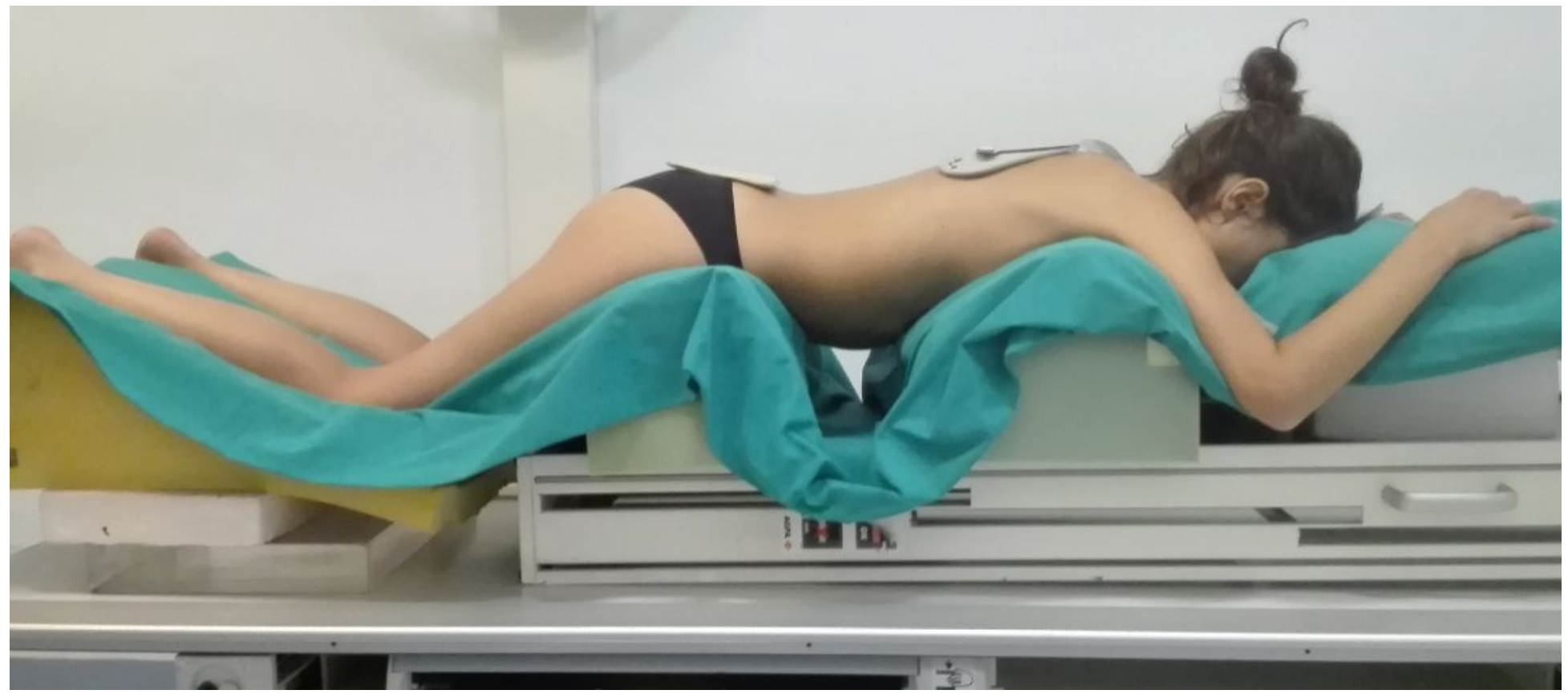

Figure 17

Prone positioning 


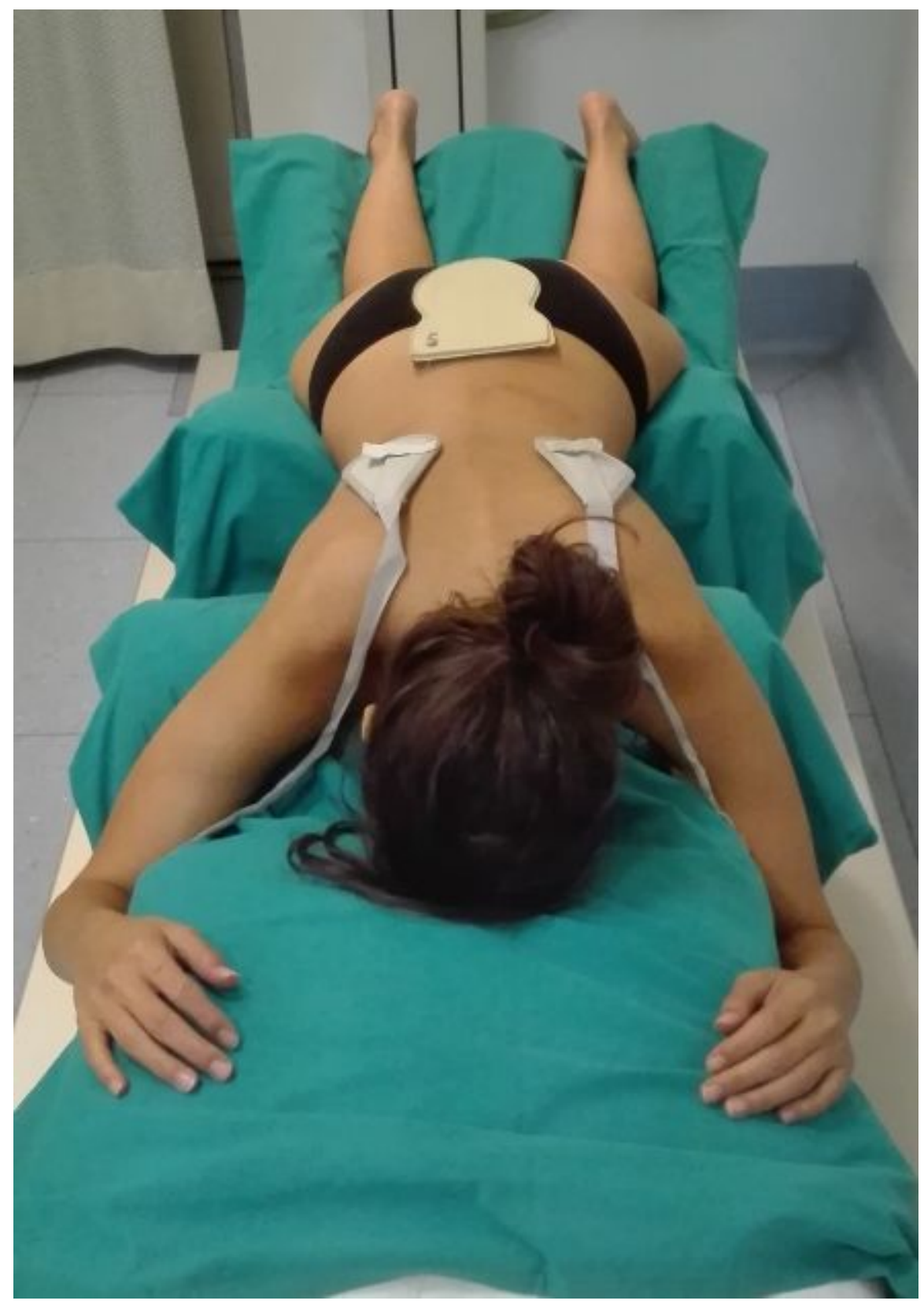

Figure 18

Prone positioning 


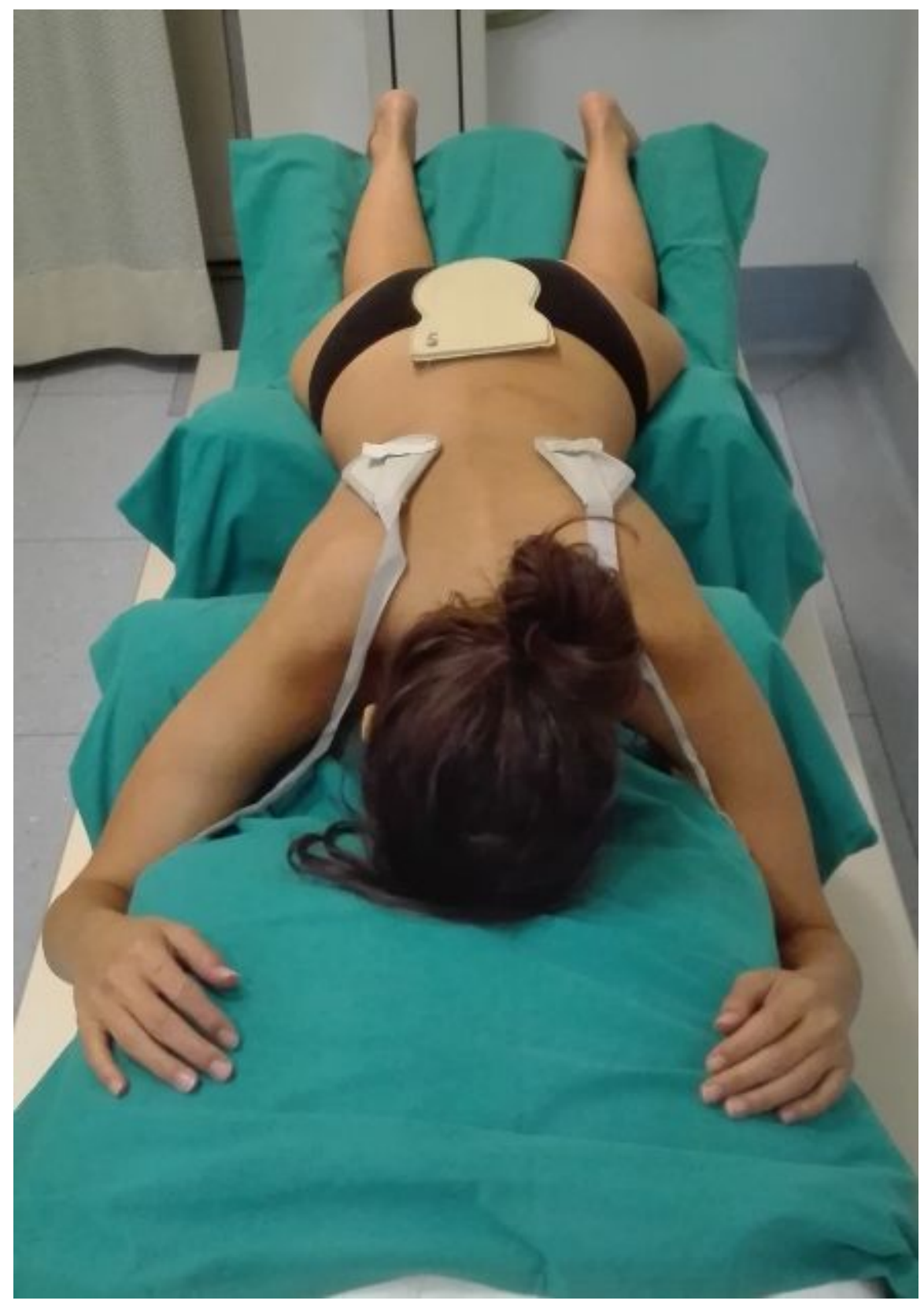

Figure 18

Prone positioning 


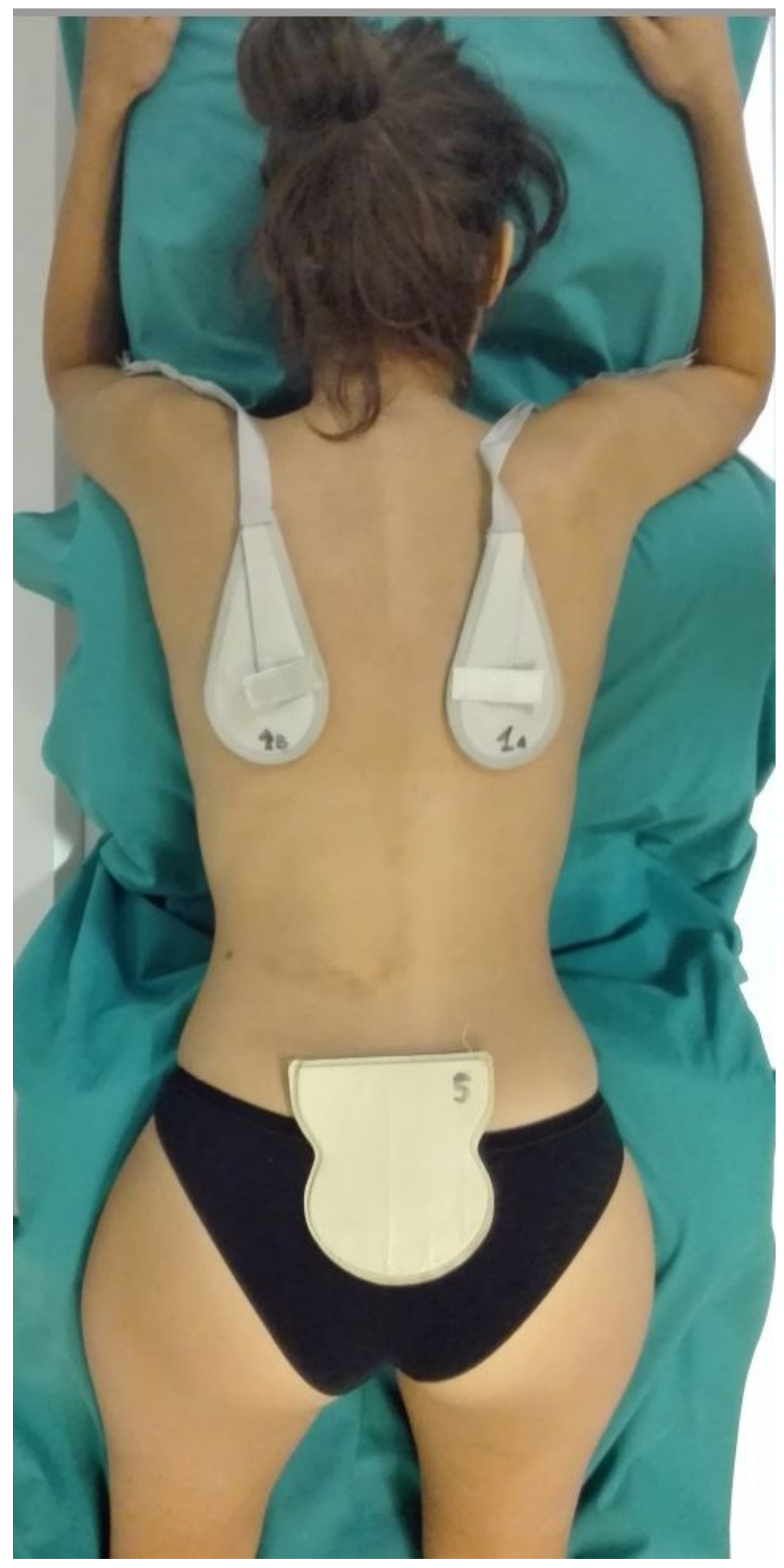

Figure 19

Prone positioning 


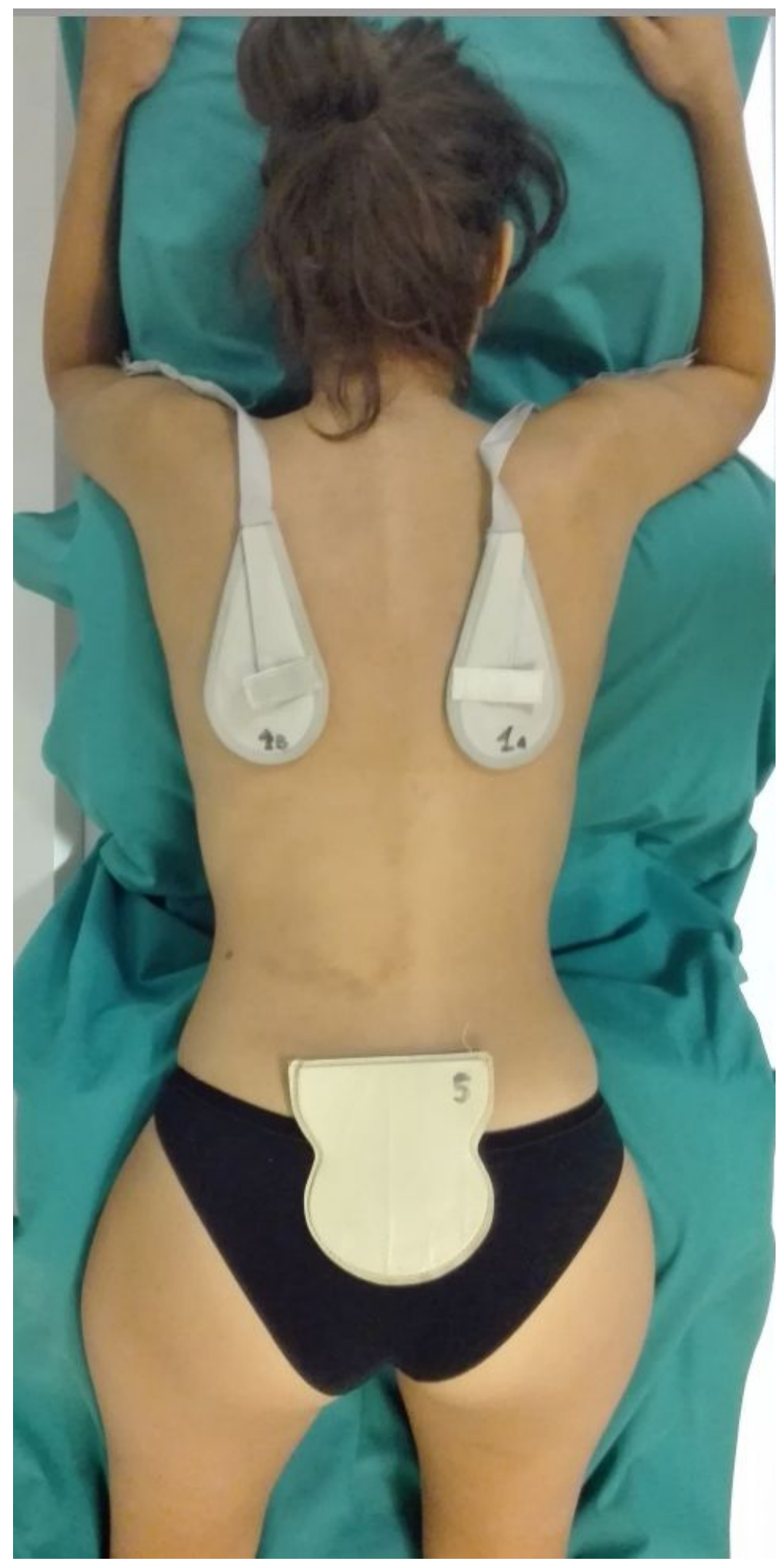

Figure 19

Prone positioning 

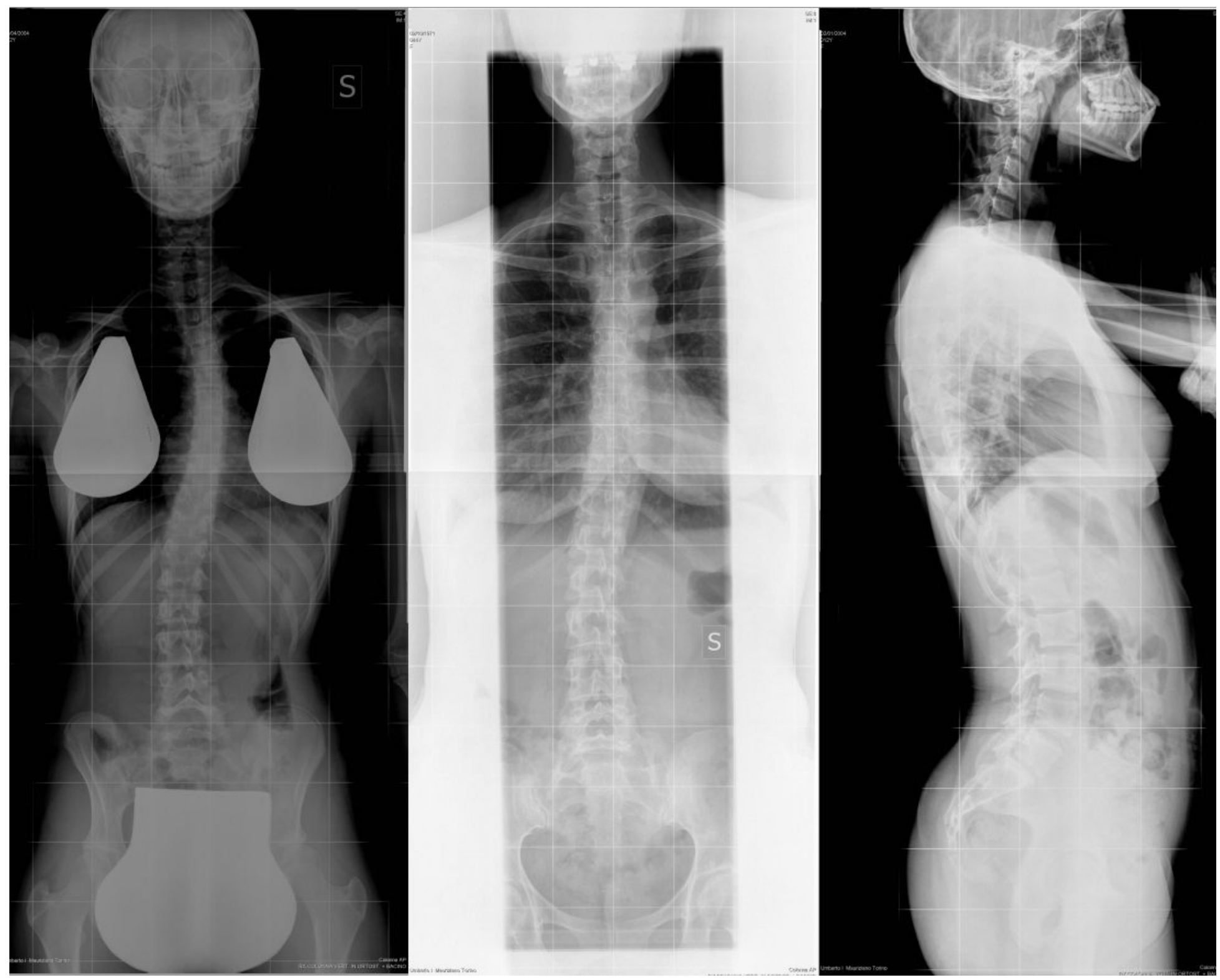

Figure 20

Examples of avoided mistakes: pelvis rotation (left) aperture (centre) upper limbs positioning (right) 

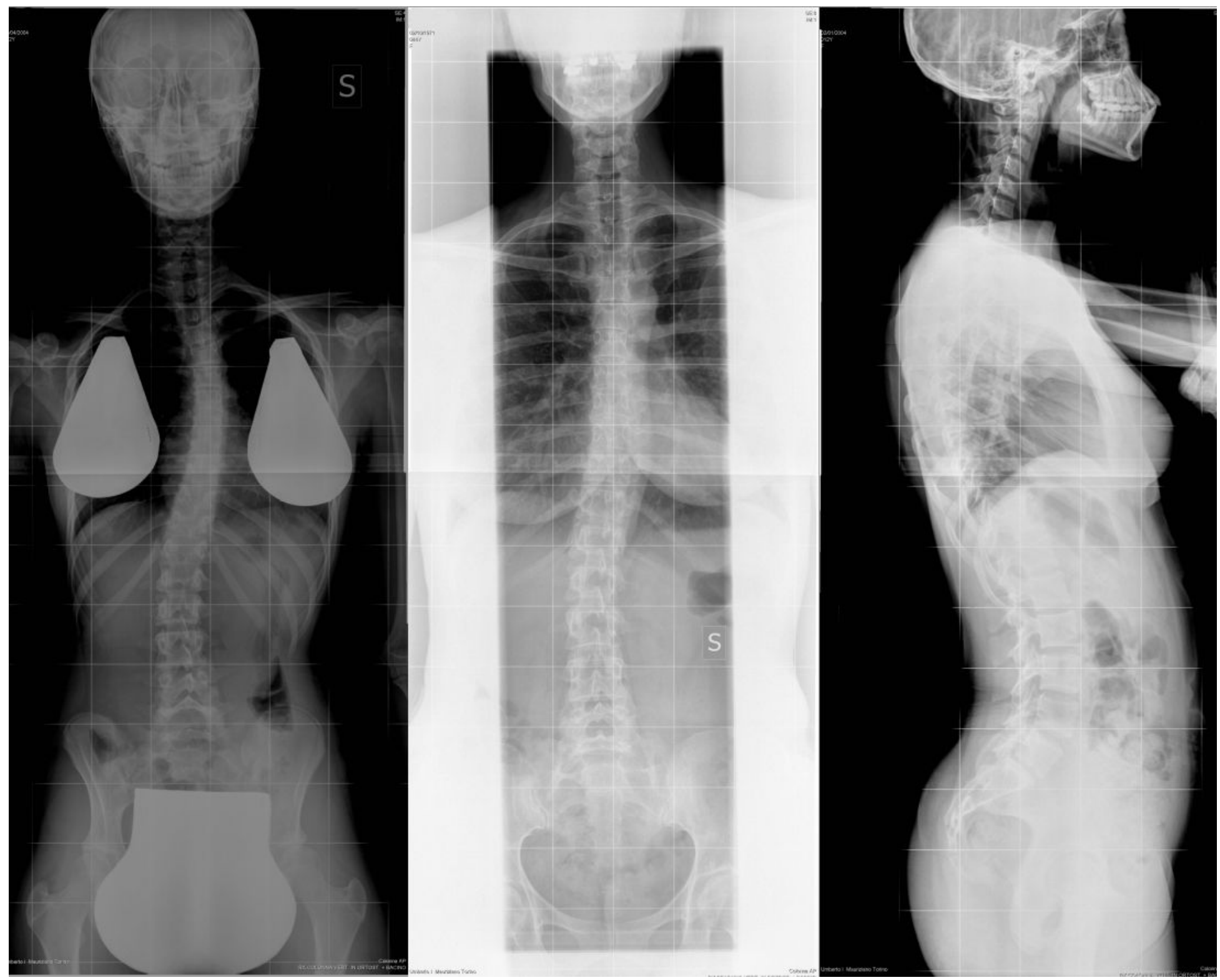

\section{Figure 20}

Examples of avoided mistakes: pelvis rotation (left) aperture (centre) upper limbs positioning (right) 


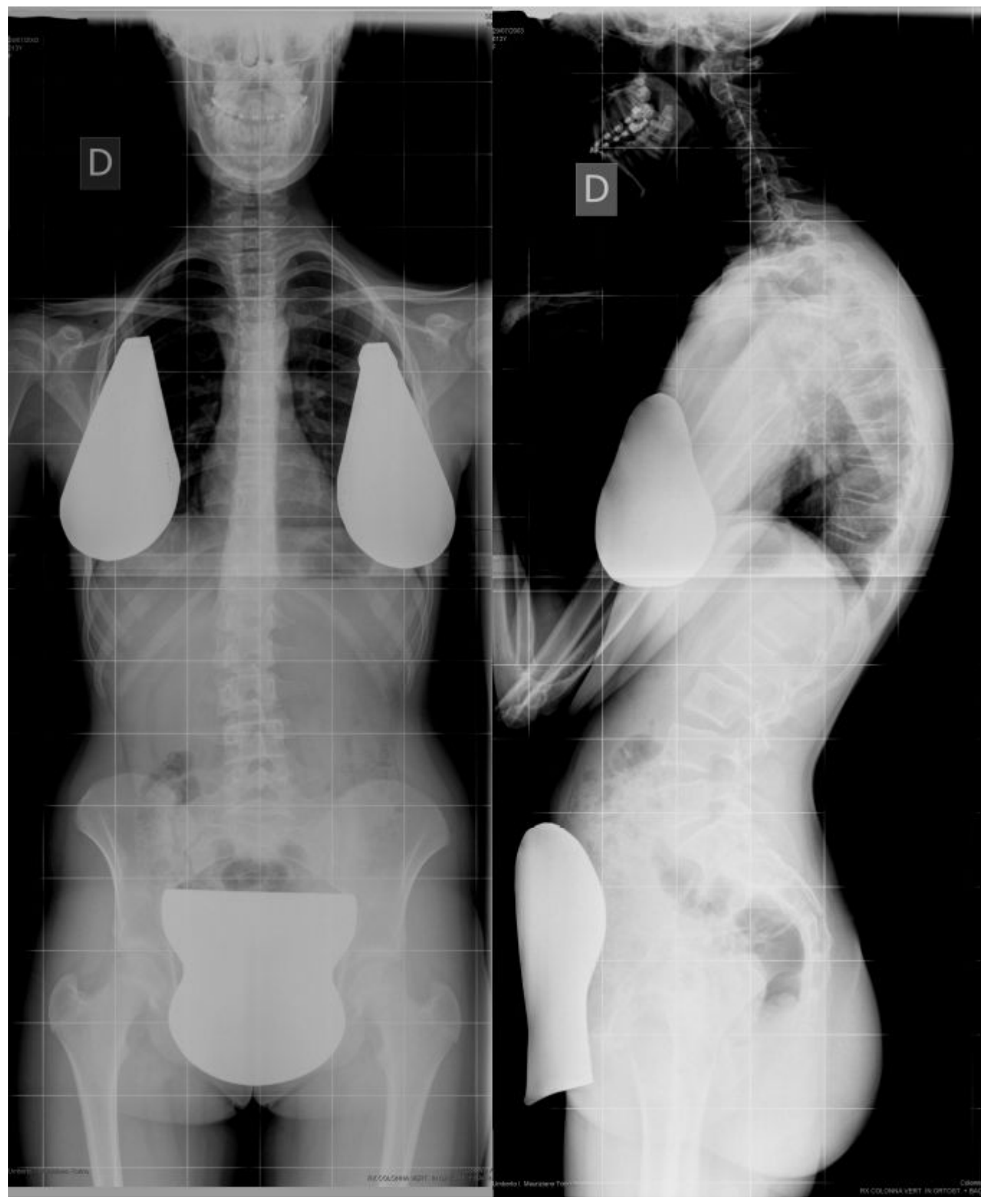

Figure 21

Examples of correct imaging: AP (left) LL (right) 


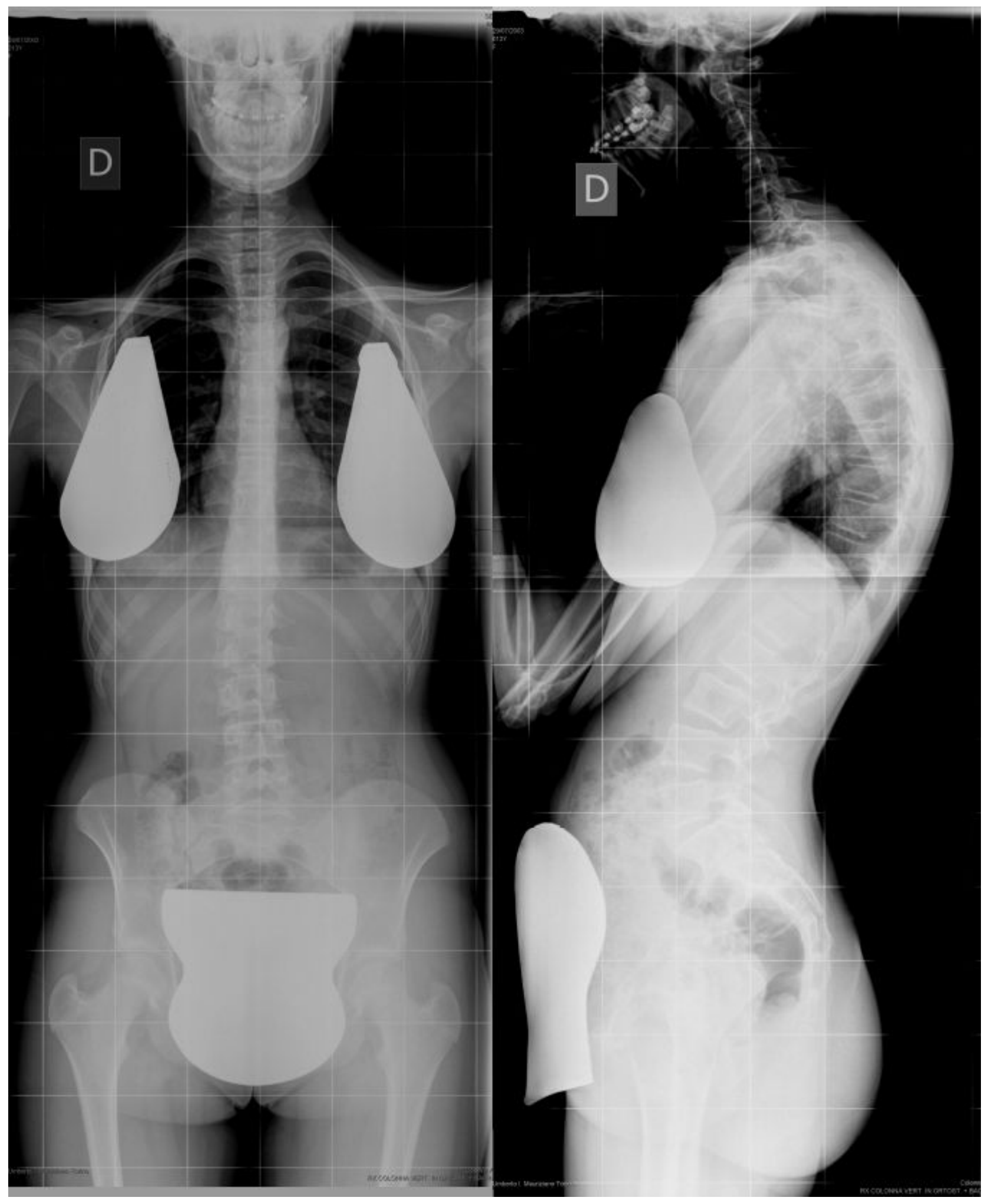

Figure 21

Examples of correct imaging: AP (left) LL (right) 